\title{
EVALUATION OF A METHOD USING COLLOIDAL GAS APHRONS TO REMEDIATE METALS-CONTAMINATED MINE DRAINAGE WATERS
}

Final Report

By

R. William Grimes

June 2002

Work Performed Under Cooperative Agreement DE-FC26-98FT40322

Subtask 2.1

For

U.S. Department of Energy

National Energy Technology Laboratory

Morgantown, West Virginia

By

Western Research Institute

Laramie, Wyoming 


\section{ACKNOWLEDGMENTS}

The author expresses his sincere appreciation to the U.S. Department of Energy, National Energy Technology Laboratory for funding this work under contract number DE-FC2698FT40322 and to the U.S. EPA Region VIII, the Wyoming Department of Environmental Quality, and the South Dakota Department of Environment and Natural Resources for recommending and supplying the samples used in this project.

\section{DISCLAIMER}

This report was prepared as an account of work sponsored by an agency of the United States Government. Neither the United States Government nor any agencies thereof, nor any of its employees, makes any warranty, expressed or implied, or assumes any legal liability or responsibility for the accuracy, completeness, or usefulness of any information, apparatus, product, or process disclosed, or represents that its use would not infringe on privately owned rights. Reference herein to any specific commercial product, process, or service by trade name, trademark, manufacturer, or otherwise does not necessarily constitute or imply its endorsement, recommendation, or favoring by the United States Government or any agency thereof. The views and opinions of authors expressed herein do not necessarily state or reflect those of the United States Government or any agency thereof. 


\begin{abstract}
Experiments were conducted in which three selected metals-contaminated mine drainage water samples were treated by chemical precipitation followed by flotation using colloidal gas aphrons (CGAs) to concentrate the precipitates. Drainage water samples used in the experiments were collected from an abandoned turn-of-the-century copper mine in south-central Wyoming, an inactive gold mine in Colorado's historic Clear Creek mining district, and a relatively modern gold mine near Rapid City, South Dakota. The copper mine drainage sample was nearly neutral ( $\mathrm{pH}$ 6.5) while the two gold mine samples were quite acidic $(\mathrm{pH} \sim 2.5)$. Metals concentrations ranged from a few $\mathrm{mg} / \mathrm{L}$ for the copper mine drainage to several thousand $\mathrm{mg} / \mathrm{L}$ for the sample from South Dakota.

CGAs are emulsions of micrometer-sized soap bubbles generated in a surfactant solution. In flotation processes the CGA microbubbles provide a huge interfacial surface area and cause minimal turbulence as they rise through the liquid. CGA flotation can provide an inexpensive alternative to dissolved air flotation (DAF). The CGA bubbles are similar in size to the bubbles typical of DAF. However, CGAs are generated at ambient pressure, eliminating the need for compressors and thus reducing energy, capital, and maintenance costs associated with DAF systems.
\end{abstract}

The experiments involved precipitation of dissolved metals as either hydroxides or sulfides followed by flotation. The CGAs were prepared using a number of different surfactants. Chemical precipitation followed by CGA flotation reduced contaminant metals concentrations by more than $90 \%$ for the copper mine drainage and the Colorado gold mine drainage. Contaminant metals were concentrated into a filterable sludge, representing less than $10 \%$ of the original volume. CGA flotation of the highly contaminated drainage sample from South Dakota was ineffective. All of the various surfactants used in this study generated a large sludge volume and none provided a significant concentration factor with this sample.

For the two samples where CGA flotation was effective, the separation was very rapid and the concentrate volume was reduced when compared to gravity separation under similar conditions. Effective separations were achieved with very low chemical dosages and low residence times, suggesting the possibility of economic viability for processes based on this concept.

The CGA flotation experiments described in the following report were conducted to provide preliminary data with which to assess the technical feasibility of using the method for remediation of metals-contaminated mine drainage waters. The experiments were conducted using common, low-cost, precipitating reagents and CGA prepared from several surfactants. Results were evaluated in terms of metals concentration reduction, reagent consumption, and concentrate volume. The results of these preliminary experiments indicate that CGA flotation may be a useful tool for the treatment of some types of mine drainage. 


\section{TABLE OF CONTENTS}

$\underline{\text { Page }}$

LIST OF TABLES AND FIGURES.........................................................................

EXECUTIVE SUMMARY …………............................................................... vii

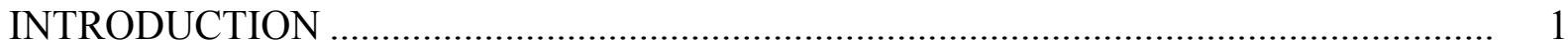

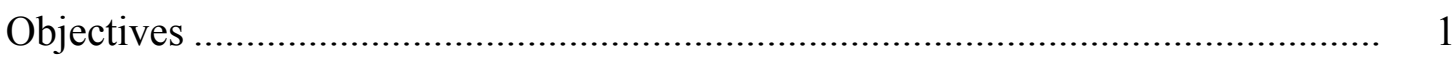

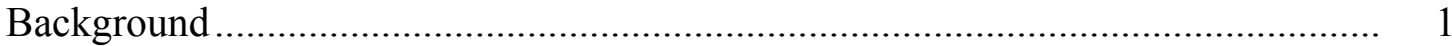

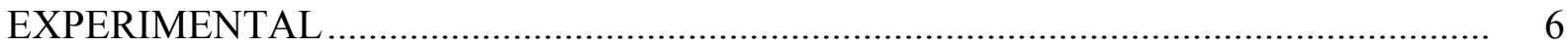

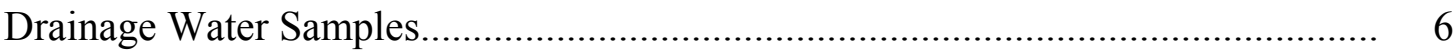

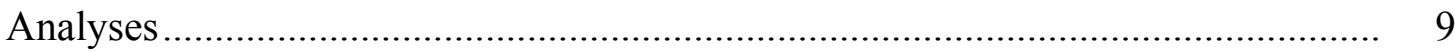

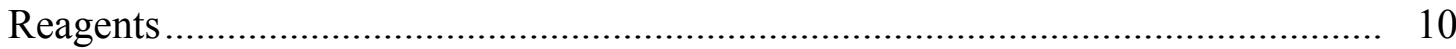

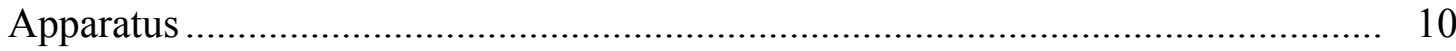

Procedures ......................................................................................... 10

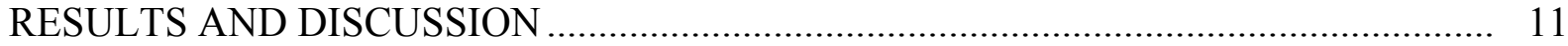

Experiments Using the Wyoming Drainage Sample ............................................... 11

Experiments Using the Colorado Drainage Sample ………..................................... 13

Experiments Using the South Dakota Drainage Sample ......................................... 17

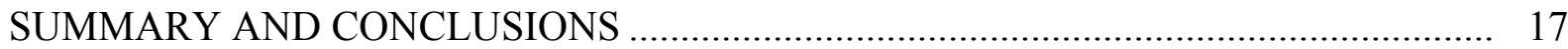

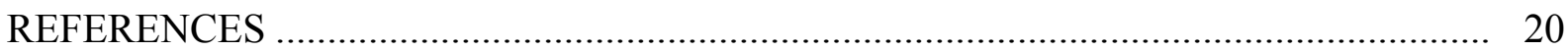




\section{LIST OF TABLES AND FIGURES}

$\underline{\text { Table }}$

$\underline{\text { Page }}$

1. Chemical Analyses of Drainage Water Samples ............................................. 8

$\underline{\text { Figure }}$

$\underline{\text { Page }}$

1. Schematic Diagram of the Experimental Apparatus........................................ 22

2. Effect of $\mathrm{pH}$ and Added Coprecipitate on Flotation of Copper

Hydroxide Precipitate ................................................................................................ 23

3. Effect of $\mathrm{Fe}^{3+}$ Concentration on Efficiency of Copper Removal by Adsorbing Colloid Flotation with $\mathrm{Fe}(\mathrm{OH})_{3}$ Coprecipitate.

4. Effect of $\mathrm{Fe}^{3+}$ Concentration on Residual Copper Concentration After Adsorbing Colloid Flotation with $\mathrm{Fe}(\mathrm{OH})_{3}$ Coprecipitate .....

5. Effect of $\mathrm{pH}$ on Residual Copper Concentration after Adsorbing Colloid Flotation with $\mathrm{Fe}(\mathrm{OH})_{3}$ Coprecipitate

6. Residual Copper Concentrations from Eighteen Adsorbing Colloid Flotation Experiments Using the Wyoming Drainage Water.

7. Effect of Increasing CGA Volume on Residual Copper

Concentration 25

8. Effect of $\mathrm{pH}$ on Metals Removal From Colorado Drainage Sample ...................... 26

9. Effect of $\mathrm{pH}$ on Metals Removal From Colorado Drainage Sample with $42 \mathrm{mg} / \mathrm{L}$ Added Sulfide

10. Effect of $\mathrm{pH}$ on Metals Removal From Colorado Drainage Sample, $10 \mathrm{mg} / \mathrm{L}$ Added Sulfide with Two-Step Flotation

11. Metals Removal Versus Surfactant Consumption for Colorado Drainage Sample... 27

12. Sludge/Foam Volume Versus Separation Time, Colorado Drainage Sample, $\mathrm{pH}$ 6.1, Triton X-100 Surfactant 


\section{LIST OF TABLES AND FIGURES (continued)}

\section{Page}

13. Sludge/Foam Volume Versus Separation Time, Colorado Drainage Sample, pH 6.7, Triton X-100 Surfactant............................................................................ 28

14. Sludge/Foam Volume Versus Separation Time, Colorado Drainage Sample, $\mathrm{pH}$ 6.4, Betz SF 5100 Surfactant 29

15. Simplified Process Flow Sheet for $100 \mathrm{~L} / \mathrm{min}$ Process Demonstration Unit 30 


\section{EXECUTIVE SUMMARY}

Experiments were conducted in which three selected metals-contaminated mine drainage water samples were treated by chemical precipitation followed by flotation using colloidal gas aphrons (CGAs) to concentrate the precipitates. Drainage water samples used in the experiments were collected from an abandoned turn-of-the-century copper mine in south-central Wyoming, an inactive gold mine in Colorado's historic Clear Creek mining district, and a relatively modern gold mine near Rapid City, South Dakota. The copper mine drainage sample was nearly neutral ( $\mathrm{pH}$ 6.5) while the two gold mine samples were quite acidic $(\mathrm{pH} \sim 2.5)$. Metals concentrations ranged from a few $\mathrm{mg} / \mathrm{L}$ for the copper mine drainage to several thousand $\mathrm{mg} / \mathrm{L}$ for the sample from South Dakota.

CGAs are emulsions of micrometer-sized soap bubbles generated in a surfactant solution. In flotation processes the CGA microbubbles provide a huge interfacial surface area and cause minimal turbulence as they rise through the liquid. CGA flotation can provide an inexpensive alternative to dissolved air flotation (DAF). The CGA bubbles are similar in size to the bubbles typical of DAF. However, CGAs are generated at ambient pressure, eliminating the need for compressors and thus reducing energy, capital, and maintenance costs associated with DAF systems.

The experiments involved precipitation of dissolved metals as either hydroxides or sulfides followed by flotation. The CGAs were prepared using a number of different surfactants. Chemical precipitation followed by CGA flotation reduced contaminant metals concentrations by more than $90 \%$ for the copper mine drainage and the Colorado gold mine drainage. Contaminant metals were concentrated into a filterable sludge, representing less than $10 \%$ of the original volume. CGA flotation of the highly contaminated drainage sample from South Dakota was ineffective. All of the various surfactants used in this study generated a large sludge volume and none provided a significant concentration factor with this sample.

For the two samples where CGA flotation was effective, the separation was very rapid and the concentrate volume was reduced when compared to gravity separation under similar conditions. Effective separations were achieved with very low chemical dosages and low residence times, suggesting the possibility of economic viability for processes based on this concept.

The CGA flotation experiments described in the following report were conducted to provide preliminary data with which to assess the technical feasibility of using the method for remediation of metals-contaminated mine drainage waters. The experiments were conducted using common, low-cost, precipitating reagents and CGA prepared from several surfactants. Results were evaluated in terms of metals concentration reduction, reagent consumption, and concentrate volume. The results of these preliminary experiments indicate that CGA flotation may be a useful tool for the treatment of some types of mine drainage 


\section{INTRODUCTION}

\section{Objectives}

The objective of this project was to provide laboratory data, using real-world samples, with which to evaluate the technical and economic feasibility of a flotation-type cleanup process in which colloidal gas aphrons (CGAs) are used to remove metallic contaminants from water.

\section{Background}

Toxic metals contamination is a serious environmental problem throughout mineralized regions of the Rocky Mountain west (USEPA, 1993). Metals draining into mountain streams from abandoned mining and milling sites have damaged thousands of miles of important aquatic habitat and impacted downstream users of these waters. Toxic metals can kill fish and other aquatic organisms in the food chain. Sufficient metals concentrations can leave streams essentially devoid of life. Mountain streams ultimately drain into larger streams and rivers. Many of these streams and rivers are used as drinking water sources for downstream cities and towns. Metals contamination can significantly increase treatment costs for users of these water sources.

Most heavy metals contamination of mountain streams is a result of mining activities. Mining operations increase metals solubility by exposing iron-containing minerals to air and water. Upon exposure, bacteria oxidize ferrous iron $\left(\mathrm{Fe}^{2+}\right)$ to ferric iron $\left(\mathrm{Fe}^{3+}\right)$ thus initiating an acid-producing reaction. This in turn lowers the $\mathrm{pH}$ of the water and increases the solubility of other metals from remaining ores and tailing piles. Because iron is commonly associated with many ore bodies, mine drainage is typically of low $\mathrm{pH}$ and many heavy metals can be dissolved in the drainage.

Much of the contamination drains from turn-of-the-century mines that have long since ceased operations. When these mines were active there was little concern about the environment. Most of the population in areas immediately affected by the contamination was involved, either directly or indirectly, in the business of extracting minerals. Few understood the toxicity of the drainage or the consequences of allowing metals-contaminated water to flow into nearby streams.

Over the past few decades, the primary use of many of these contaminated areas has shifted from minerals extraction to recreational and tourism-type activities. Concern for the environment has increased, and a better understanding of the health risks associated with exposure to trace amounts of heavy metals has developed. Cleanup of metals-contaminated mine drainage has become an environmental priority. 
Cleanup of this contamination using available technologies has proven to be quite difficult and expensive. A significant factor contributing to the difficulty of cleaning up metalscontaminated streams is the remoteness of the locations often associated with the sources of contamination. Poor accessibility, abrupt terrain with little level ground, and long, hard winters are typical of many of these Rocky Mountain mining locations. In addition, many sites are located in otherwise pristine areas that are often historically significant. Costs for construction, operation, and maintenance are all increased for treatment facilities operated in these remote locations, often to the point where treatment becomes impractical.

Ulman (1986) cites three criteria that are of prime importance in the selection of cleanup processes for the remediation of metals-contaminated waters. First, the selected process must be capable of consistently reducing metals concentrations sufficiently to meet the discharge limitations that are applicable at the site. Second, the process must be economically viable. The total cost of the process including reagents, capital equipment, operating and maintenance costs, and sludge disposal must be competitive with other available methods. Finally, the process should produce a minimum amount of sludge. In remote locations the second and third criteria are closely interrelated in that sludge disposal can represent a significant portion of the overall cleanup cost.

The typical industrial practice for removing dissolved metals from large volumes of water usually involves three separate operations: chemical precipitation, separation of the wet precipitate into a small volume of the liquid, and subsequent dewatering and disposal of the precipitate. While a number of alternative processes are available for the cleanup of metalscontaminated waters, chemical precipitation is frequently the most economically attractive option, particularly when treatment volumes are large and metals concentrations are relatively high.

Chemical precipitation involves the addition of reagents to produce metallic salts of low solubility. Precipitation of the relatively insoluble hydroxide at alkaline $\mathrm{pH}$ is probably the most common treatment used to remove most heavy metals from solution (Patterson, 1985). Sulfide precipitation, though less frequently employed, is also highly effective for the separation of heavy metals from waste waters (Bhattacharyya et al., 1979). The combination of hydroxide and sulfide precipitation has also been reported as potentially useful for mine drainage cleanup. Whatever reagents are used there is a stoichiometry that must be met by the addition of a sufficient quantity of the precipitating reagent. The precipitation step is relatively uncomplicated, requiring only a mixer with a few minutes retention time and a method for metering the reagents.

In theory, cleanup could be accomplished by filtering precipitates from the bulk mixture after the addition of precipitating reagents. In practice, an additional step is usually employed to separate the precipitates from the bulk liquid and concentrate them into a small portion of the original volume. This step substantially reduces the liquid volume that must be handled by the 
dewatering system. Savings realized in the dewatering process due to the reduced liquid volume offset the cost of this additional separation step.

Some type of filtration operation is usually employed to accomplish the dewatering. Filters are designed and sized to accommodate both the liquid volume and the solids content of the mixture to be filtered with allowance for a reasonable interval before cleaning or replacement. Filtration is a relatively expensive operation. This expense depends on the nature of the precipitates and the volumes of solids and liquid that must be handled by the filtration unit. An efficient preconcentration step can provide a significant reduction in the size and cost of a filtration (dewatering) system.

Stoichiometry limits what can be done to improve the precipitation step. Reagent requirements are dictated by the chemistry of the particular drainage, and a sufficient amount of reagent must be added for effective precipitation. It is in the separation and dewatering of the precipitate, in which stoichiometry is not a limiting factor, where improvements over traditional technologies are possible. Improvements to these steps may help to increase the applicability of chemical precipitation-type treatments for use at remote locations.

The concentration of precipitate into a smaller volume is accomplished either by sedimentation or flotation. In sedimentation processes the force of gravity causes solid precipitate particles to settle to the bottom of a vessel where they are concentrated as a wet sludge. In flotation processes precipitates are buoyed to the surface by attachment to tiny air bubbles. Solids are concentrated at the surface in the form of a wet foam. In both processes the object is to concentrate the solid precipitate into a small volume. The efficiency of either of these processes can be measured in terms of precipitate recovery and concentrate volume.

Sedimentation is a "classic" technology that is well known and easily understood, operationally simple, and very reliable. Operating costs for sedimentation units are quite low with gravity supplying the majority of the energy requirements. These factors largely account for the common use of sedimentation to concentrate solid precipitates. Sedimentation processes are practical for solids concentrations ranging from $20-10,000 \mathrm{mg} / \mathrm{L}$ with particle sizes from 100-2000 $\mu \mathrm{m}$. Both upper limits are based on typical practice. There is no technical impediment to removal of larger particles or operation with higher concentrations.

Sedimentation is, necessarily, a slow operation unless the precipitate particle size is rather large. High velocities impede settling of fine particles, resulting in considerable carryover of solids in the effluent. Constructing the large sedimentation basins needed to provide the long retention times required to achieve good solids separation can be quite expensive in remote, mountainous locations. Accommodations for severe weather can also dramatically increase construction costs for sedimentation operations. Heavy snowfalls and extended periods of subfreezing cold can disrupt the operation of sedimentation units. Enclosures for these large facilities are expensive and can detract from regional aesthetics. In areas where little or no level ground is available, construction of settling basins may be very difficult or even impossible. 
Compared to sedimentation, flotation concentrates precipitates quite rapidly. The faster separation provided by flotation allows much greater hydraulic loading capacities (Kiuru, 1990) and hence, the use of smaller vessels for the treatment of a given flow volume. Flotation can also concentrate precipitates into a smaller volume with subsequent savings in dewatering costs. Flotation processes can be used for solids concentrations ranging from $10-4,000 \mathrm{mg} / \mathrm{L}$ with particle sizes from 10-2000 $\mu \mathrm{m}$. For flotation-type processes the lower limit for solids concentration is based primarily on economic considerations. The upper limit is based on operational practicality. The smaller vessels used in flotation processes can allow for off-site modular construction, significant savings in the cost of enclosing the units for weather protection, and construction in areas where little level ground is available.

Flotation is employed less frequently than sedimentation largely because of higher capital, operating, and maintenance costs and the greater complexity associated with the process. The small bubbles on which the precipitate is buoyed can be generated either by dissolving gas under pressure in the liquid and then releasing the pressure (dissolved air flotation), or by sparging the gas into the liquid through the small openings of a frit. The bubbles generated in dissolved air flotation (DAF) are typically much smaller than bubbles produced by sparging. The smaller bubbles provide a much larger interfacial surface and impart less turbulence as they rise, making DAF the preferred option for water-treatment applications. DAF systems typically operate at three to four atmospheres pressure (Feris, 1999). Sparged air systems require sufficient pressure to overcome the pressure drop of the frit. The compressors used to supply this pressure are costly, require regular maintenance, have limited life spans, and consume a good deal of energy.

Another factor contributing expense to the flotation process is the cost of flotation reagents. Various surfactant-type reagents are used to provide a surface charge on the air bubbles that serve to attract oppositely charged precipitate particles. Surfactants also serve to produce stable foam that can be removed, with the associated precipitate, from the surface of the liquid. Even though surfactants are typically used in rather low concentrations ( 40-100 mg/L), they are relatively expensive and can add significantly to the overall cost of the treatment process.

A number of researchers have investigated the use of various flotation technologies to improve solids/liquid separation in the treatment of heavy metals-contaminated waters. Clarke and Wilson (1983) provide a good review of the variety of applications of conventional flotation technologies. Haung and Wilson (1976) reported the separation of mercury and cadmium from aqueous solution by coprecipitation with cupric sulfide followed by flotation using hexadecyltrimethylammonium bromide (HTA) as the collector (surfactant). Initial copper concentrations of $100 \mathrm{mg} / \mathrm{L}$ were reduced to less than $0.5 \mathrm{mg} / \mathrm{L}$ and cadmium and mercury were removed nearly quantitatively over a broad $\mathrm{pH}$ range. Separation of copper hydroxide from an aqueous mixture using precipitate flotation was reported by Choi and Ihm (1988). The reported 
experiments used sodium dodecyl sulfate (DDS) as the collector and $\mathrm{Fe}(\mathrm{OH})_{3}$ as a coprecipitate. Both methods provided good removal efficiencies; however, rather high surfactant concentrations, 50-100 mg/L, and long foaming times, 30 minutes, were used.

Each of the methods commonly used for concentrating precipitates has specific advantages and disadvantages. With respect to application at the remote sites often associated with the sources of metals contamination, a solids/liquid separation process with a small size, large treatment capacity, high concentration factor of flotation, and the simplicity and low energy requirements of sedimentation would be desirable. Such a process could help to increase the viability of chemical precipitation-type treatments for cleanup of metals-contaminated mine drainage at the remote locations where much of this contamination originates.

Studies conducted by Seba (Scamehorn, 1989) demonstrated that flotation using colloidal gas aphrons (CGAs) can quickly and efficiently separate metallic precipitates from aqueous mixtures. CGAs are emulsions of micrometer-sized gas bubbles in a surfactant solution. The emulsions can be prepared easily and at low cost using simple apparatus. CGA emulsions are relatively stable and can easily be pumped from one container to another with little coalescence of the minute bubbles.

CGA bubbles are spherical and range in size from 25 to $100 \mu \mathrm{m}$ in diameter. The small size and spherical shape of the bubbles provide a very large interfacial surface and an emulsion that flows as easily as water. The large interfacial surface area and high fluidity of CGAs produce a system with considerable potential for improving flotation-based separation processes. Flotation processes using CGAs could represent a simple, low-cost alternative to sedimentation or conventional flotation for the concentration of precipitates from chemically treated mine drainage waters. These processes may provide the basis for an improved water cleanup technology that could be practical for use at remote sites.

When CGA is pumped to the bottom of a flotation column, the micrometer-sized bubbles rise as a swarm through the liquid in the column, presenting a huge surface area that is available for precipitate adsorption. This surface can be strongly attractive toward selected precipitates if the appropriate surfactant/surfactants are used to prepare the CGA. The bubbles touch each other in a weakly linked matrix, but do not coalesce significantly in the time required for most flotation operations. Instead, the linked bubbles rise as a mass, capturing particulates encountered on their path to the surface. The matrix structure provides for a thorough contacting between bubble surfaces and the column liquid. Thus, CGA flotation can provide a high recovery of precipitates in a short time.

A spinning disk mounted between two stationary, vertical baffles can be used to generate CGA. The disk is submerged just below the surface of a surfactant solution and rotated at a high velocity. The rapidly rotating disk produces waves on the surface of the solution. These waves beat up against the baffles where they entrain a thin film of gas. The thin film of gas is unstable and breaks into minute bubbles encapsulated in a soapy shell (CGA). Once the disk is spinning, 
very little energy is required to sustain its motion. Seba has estimated that only one kilowatthour of energy would be required for the generation of ten thousand liters of CGA (Scamehorn, 1989). In many headwater locations this small energy requirement could be supplied by the hydrodynamic force available in the flowing stream, or in some cases, from the drainage itself. While other methods can be used to generate CGA (Shea and Barnett, 1979), the spinning disk system is extremely simple and, if properly constructed, should require almost no maintenance.

Preliminary experiments have been conducted using CGA-enhanced precipitate flotation to remove metallic contaminants from mine drainage water samples. Metals were precipitated as either the sulfide or the hydroxide, then floated with CGA emulsions prepared using several different surfactants. Significant variables included precipitant, method of CGA application, surfactant type, $\mathrm{pH}$, added coprecipitate, and CGA volume. The results of these experiments are the subject of this report.

\section{EXPERIMENTAL}

\section{Drainage Water Samples}

Metals-contaminated water samples were obtained from drainages in Wyoming, Colorado, and South Dakota. The samples were selected based on recommendations from various state and federal regulatory agencies concerned with the cleanup of mine drainage. The selected samples contained a variety of dissolved metals with concentrations ranging from a few to several thousand $\mathrm{mg} / \mathrm{L}$. Sample $\mathrm{pH}$ ranged from near neutral (6.5) to acidic (2.5). In addition to the actual drainage water samples, a surrogate sample containing known concentrations of copper was prepared for use in some of the preliminary experiments.

The drainage sample from Wyoming came from the Ferris-Haggarty Mine. The sample was obtained with permission of the Wyoming Department of Environmental Quality, Division of Abandoned Mine Lands, and the mine's current owner. The Ferris-Haggarty is an inactive copper mine in the Sierra Madre Mountains in south-central Wyoming near the town of Encampment. Copper-contaminated water draining from the one-hundred-year-old mine tunnel has poisoned a section of a nearby stream, so that it can no longer support an important population of native cutthroat trout. The site is historic and remote, has no utilities, and is almost inaccessible throughout the winter months during which the area can be covered by up to ten feet of snow.

Copper is not particularly toxic to humans, with up to $1 \mathrm{mg} / \mathrm{L}$ being acceptable in drinking water (USEPA, 1973). Copper is, however, quite toxic to fish and aquatic microorganisms. Mckee and Wolfe (1963) report that a copper concentration of only $0.14 \mathrm{mg} / \mathrm{L}$ in fresh water can be toxic to trout, and even lower concentrations can be toxic to various types of plankton. An agreement between the various concerned state agencies established an aftercleanup target level for residual copper of $0.15 \mathrm{mg} \mathrm{Cu} / \mathrm{L}$ for this drainage. This target level, after 
subsequent dilution in the stream into which the discharge flows, will result in a copper concentration well below toxic levels and allow for the desired recovery of aquatic habitat.

Representative samples of the Ferris-Haggarty drainage water taken under controlled conditions contain both suspended and dissolved copper. Sediment-free samples of the drainage, taken at various times throughout the year averaged $3.45 \mathrm{mg} / \mathrm{L}$ of dissolved copper, and 0.84 $\mathrm{mg} / \mathrm{L}$ of suspended copper for a total of $4.28 \mathrm{mg} / \mathrm{L}$ (Adrian Brown Consultants, 1994). In addition to copper the Ferris-Haggarty drainage water contained sulfur and small amounts, compared to the copper concentration, of dissolved silicon, aluminum, calcium, magnesium, and potassium (Knight Piesold, 1997).

The grab sample obtained for use in these experiments was taken from a small settling pond into which the drainage from the mine discharges before flowing into a nearby stream. This sample contained a considerable quantity of copper-rich sediment, and when thoroughly mixed so that all the solids were suspended, it contained $14.8 \mathrm{mg} / \mathrm{L}$ total copper. Upon standing undisturbed for 12 hours larger particles settled out, leaving a clear liquid with a copper concentration of $2.5 \mathrm{mg} / \mathrm{L}$. The copper concentration in the sample decreased slowly with time ( $\sim 0.1 \mathrm{mg} / \mathrm{L}$ per week), apparently due to the gradual settling of finer particles. The copper concentration in this sample, as measured prior to each experiment, ranged from $\sim 2.5$ to $\sim 1.5$ $\mathrm{mg} / \mathrm{L}$ over the course of the experiments. The $\mathrm{pH}$ of the sample was $\sim 6.5$.

The drainage sample from Colorado came from the Argo Tunnel. The tunnel collects drainage from several historic gold mines and discharges into the nearby Clear Creek. This sample was recommended by the United States Environmental Protection Agency (U.S. EPA) Region VIII mine waste team leader. The outlet of the Argo Tunnel is near Idaho Springs, Colorado, and is in the Clear Creek Superfund site. Drainage from the Argo Tunnel is currently being treated with a chemical precipitation and sedimentation process before it is discharged into Clear Creek.

Clear Creek supplies drinking water for more than 165,000 downstream users. A small number of mines are still active in the Clear Creek watershed region. However, recreational activities and limited-stakes gambling in two small communities are rapidly becoming the mainstay of the area's economy (U.S. EPA, 1997).

The U.S. EPA, the U.S. Geological Survey, the Upper Clear Creek Watershed Association, and the Colorado Department of Public Health and Environment have conducted extensive studies of the Argo Tunnel drainage water. Significant concentrations of dissolved aluminum, cadmium, copper, iron, lead, manganese, nickel, strontium, and zinc were reported for this drainage as well as lower concentrations of several other metals. The major anionic constituent of this drainage is sulfate. The $\mathrm{pH}$ of this drainage is $\sim 2.5$. 
The drainage sample from South Dakota came from a relatively modern gold mining operation near Rapid City. This sample, supplied by the South Dakota Department of Environment and Natural Resources, Minerals and Mining Office, is representative of a very difficult drainage problem. The mine is still considered to be active, but minerals extraction has been largely curtailed due to drainage water problems that have developed in the pit. Because of the active status of this mine, the sample is identified only as the South Dakota sample.

Of the three samples used in this study, the South Dakota sample contained the highest concentrations of dissolved metals. Significant concentrations of dissolved aluminum, cadmium, copper, iron, manganese, nickel, strontium, and zinc were present in this drainage sample. The South Dakota sample had a pH of 2.66, with the major anionic constituent being sulfate.

Table 1 shows the typical chemical analyses of the Colorado and South Dakota drainage water samples used in the experiments. Data shown in the table was provided by the various agencies that recommended or supplied the samples. The values presented in Table 1 represent the average of a number of individual analyses provided for these drainage waters.

Table 1. Chemical Analyses of Drainage Water Samples

\begin{tabular}{llll}
\hline Parameter & Unit & CO & SD \\
\hline Flow & $\mathrm{cfs}$ & 0.46 & \\
$\mathrm{pH}$ & $\mathrm{s} . \mathrm{u}$. & 2.63 & 2.66 \\
Dissolved Solids & $\mathrm{mg} / \mathrm{L}$ & 3465 & 8798 \\
Aluminum & $\mathrm{mg} / \mathrm{L}$ & 27.6 & 453 \\
Arsenic & $\mu \mathrm{g} / \mathrm{L}$ & 145 & 464 \\
Boron & $\mu \mathrm{g} / \mathrm{L}$ & 192 & 0 \\
Cadmium & $\mu \mathrm{g} / \mathrm{L}$ & 213 & 1520 \\
Cobalt & $\mu \mathrm{g} / \mathrm{L}$ & 179 & 2300 \\
Copper & $\mathrm{mg} / \mathrm{L}$ & 5.7 & 74.9 \\
Iron & $\mathrm{mg} / \mathrm{L}$ & 159 & 291 \\
Lead & $\mu \mathrm{g} / \mathrm{L}$ & 111 & 3 \\
Manganese & $\mathrm{mg} / \mathrm{L}$ & 100 & 214 \\
Molybdenum & $\mu \mathrm{g} / \mathrm{L}$ & 0.0 & 22 \\
Nickel & $\mu \mathrm{g} / \mathrm{L}$ & 309 & 1570 \\
Silver & $\mu \mathrm{g} / \mathrm{L}$ & 3.2 & $<1$ \\
Strontium & $\mu \mathrm{g} / \mathrm{L}$ & 1247 & 1230 \\
Zinc & $\mathrm{mg} / \mathrm{L}$ & 58.7 & 19.3 \\
Sulfate & $\mathrm{mg} / \mathrm{L}$ & 2032 & 4609 \\
Chloride & $\mathrm{mg} / \mathrm{L}$ & 6.3 & 34 \\
Fluoride & $\mathrm{mg} / \mathrm{L}$ & 2.4 & 62.6 \\
\hline & & & \\
\hline
\end{tabular}


The surrogate sample was prepared by dissolving a weighed quantity of clean, bright copper turnings in $10 \%$ nitric acid and diluting this solution with tap water to give the desired concentration. This sample served as a control for several of the preliminary experiments, and to verify calibration of the colorimeter used to determine copper concentrations in experiments with the Ferris-Haggarty sample.

\section{$\underline{\text { Analyses }}$}

A Hach Pocket Colorimeter was used to measure copper concentration in the feed and residual copper concentration in the cleaned waters for experiments using the Wyoming drainage water sample.

The colorimeter was a portable, single-wavelength instrument. Prepackaged reagents designed specifically for measuring the concentration of copper in water were used for the analyses. The bicinchoninate reagent that was used in the analyses reacts with $\mathrm{Cu}^{1+}$ to form a purple-colored complex. The intensity of the purple color, as measured by the colorimeter, is proportional to the copper concentration. The reagent package also contained a buffer and reducing agent to reduce $\mathrm{Cu}^{2+}$ to $\mathrm{Cu}^{1+}$ so that all of the uncomplexed copper was measured by the method.

The prepackaged reagents used for these analyses were not sensitive to copper complexes that could also have been in solution. However, digested and undigested samples of the untreated water showed nearly identical copper concentrations; indicating that little, if any, copper was in the form of copper complexes.

For experiments in which the copper was precipitated by the addition of hydroxide ions, digested and undigested samples showed nearly identical copper concentrations. Consequently, these samples were analyzed without digestion. Samples precipitated by the addition of sulfide ions were digested using an EPA-approved, mild digestion procedure (Hach Water Analysis Handbook, 1992) prior to analysis.

Inductive coupled plasma atomic emissions spectroscopy (ICP-AES) was used for analyses of the more complex samples. ICP analysis is a spectroscopic technique that uses an argon plasma as the excitation source. Samples are introduced into the plasma and heated to temperatures that assure complete atomization. The spectrum emitted by the highly excited ionized sample is observed just above the plasma flame. The sample spectrum is compared to reference spectrums and a quantitative measure of the elemental composition of the sample is established. Wyoming Analytical Laboratories conducted the ICP-AES analyses for this study.

An Amber Science 4503A Solution Analyzer with a Cole-Parmer double-junction $\mathrm{Ag} / \mathrm{AgCl}$ electrode was used for $\mathrm{pH}$ measurements. 


\section{Reagents}

Sodium hydroxide (MCB Reagents), calcium hydroxide (Aldrich), and sodium sulfide (EM Science) were used as precipitating reagents. Ferric chloride (J.T. Baker) was used to provide $\mathrm{Fe}^{3+}$ ions for coprecipitation in some experiments.

Hexadecyltrimethylammonium bromide (HTA) (Eastman Kodak), sodium dodecyl sulfate (DDS) (Aldrich), Triton X-100 (Union Carbide), Depositrol SF5100 (Betz Dearborne), Surfonic N-95 (Texaco), and the sodium salt of oleic acid (EM Science) were used as surfactants for the preparation of CGA.

\section{$\underline{\text { Apparatus }}$}

The experimental apparatus consisted of a CGA generator similar to that described by Seba (1989), a $175-\mathrm{cm}^{3} / \mathrm{min}$ chemical metering pump, a loop of polyethylene tubing with a tee and valve, and a graduated glass column with a $3.5-\mathrm{cm}$ inside diameter and a height of $25 \mathrm{~cm}$. The metering pump was connected to circulate CGA from the generator through the loop and back to the reservoir. The tee and valve provided a small flow of the circulating CGA to an orifice at the bottom of the column. The orifice consisted of a 5-cm length of $0.75-\mathrm{mm}$ (inside diameter), stainless-steel tubing that passed through the center of a rubber stopper that served to close the bottom of the column. A second hole in the rubber stopper was fitted with a valve through which the column could be drained and sampled.

The CGA generator consisted of a standard 3-L beaker and a support structure used to hold a stirring motor, center bearing, and impeller as well as a plexiglass cover to which a pair of plexiglass baffles were attached. A rapidly spinning impeller mounted between two baffles and submerged a few centimeters below the surface of a surfactant solution was used to generate CGA. The impeller was made from a disk of stainless steel, $1.5 \mathrm{~mm}$ thick and $6.5 \mathrm{~cm}$ in diameter, with radial slots cut so as to divide the disk into four equal segments. A high-speed stirring motor mounted above the center of the beaker was used to drive the impeller.

The experimental apparatus with flotation column, circulating loop, and CGA generator is shown schematically in Figure 1.

\section{Procedures}

For a typical experiment, a volume of one of the drainage water samples was measured into a small beaker. A pH electrode was placed in the beaker, and the initial $\mathrm{pH}$ of the sample was measured and recorded. The beaker was then placed on a magnetic stirrer and stirred 
vigorously while the precipitating reagents were added. Rapid stirring was continued until the $\mathrm{pH}$ of the mixture stabilized (usually about five minutes), and the $\mathrm{pH}$ was recorded. The stirring speed was then reduced, and stirring was continued at very low intensity for an additional 3 to 5 minutes. The final $\mathrm{pH}$ of the mixture was measured and recorded.

After reagent addition and stirring, the mixture was poured into the flotation column. A small volume of CGA (made from a solution containing $\sim 330 \mathrm{mg} / \mathrm{L}$ of surfactant) was admitted at the bottom of the column by opening the valve in the circulating loop for a few seconds. The volume of CGA added was recorded, and the column was allowed to stand undisturbed while the CGA bubbles rose to the surface. After the bubbles had risen and the column liquid cleared, the liquid and foam volumes were measured and recorded. Samples of the cleaned liquid were removed by means of the column drain valve for subsequent analyses. Foam samples were removed from the surface using a pipette with a suction bulb.

\section{RESULTS AND DISCUSSION}

\section{Experiments Using the Wyoming Drainage Sample}

Two experiments were conducted using the Wyoming drainage water sample with sulfide precipitation followed by CGA flotation. For these experiments, sodium sulfide solution was added to the drainage water sample to provide an initial sulfide concentration of $7.5 \mathrm{mg} / \mathrm{L}$. The resulting mixture had a $\mathrm{pH}$ of $\sim 8.5$. This mixture was transferred to the column and treated with CGA generated from a solution of HTA. Analysis of the column liquid after CGA treatment showed no reduction in copper concentration for either experiment.

Two additional sulfide precipitation/CGA flotation experiments were conducted using prepared samples with copper concentrations considerably higher than that of the Wyoming drainage water sample. Initial copper concentrations of $48 \mathrm{mg} / \mathrm{L}$ and $84 \mathrm{mg} / \mathrm{L}$ were used in these experiments. In the first experiment, sodium sulfide solution was added to a sample containing $48-\mathrm{mg} / \mathrm{L} \mathrm{Cu}$ to provide an initial sulfide concentration of $22.5 \mathrm{mg} / \mathrm{L}$. Sodium hydroxide solution was added to adjust the $\mathrm{pH}$ to $\sim 9.2$. Flotation in the column with CGA prepared from HTA reduced the copper concentration in the column liquid to $3.2 \mathrm{mg} / \mathrm{L}$, a reduction of $\sim 93 \%$. For the second experiments, sodium sulfide solution was added to a sample containing $84-\mathrm{mg} / \mathrm{L} \mathrm{Cu}$ to provide an initial sulfide concentration of $45 \mathrm{mg} / \mathrm{L}$. Residual copper after CGA treatment was $3.9 \mathrm{mg} / \mathrm{L}$, or $\sim 95 \%$ reduction.

Huang and Wilson (1976) reported flotation of copper sulfide precipitate from a solution with an initial concentration of $100 \mathrm{mg} \mathrm{Cu} / \mathrm{L}$ using HTA and sparged air bubbles. Residual copper concentrations after flotation were reported as $<0.5 \mathrm{mg} / \mathrm{L}$. Considering that Huang and Wilson began flotation with a surfactant concentration of $40 \mathrm{mg} / \mathrm{L}$ and continued foaming with subsequent surfactant additions for 30 minutes, CGA flotation of the prepared solutions compared favorably with these results. Surfactant consumption, with respect to column liquid, 
for the CGA flotation was only about $10 \mathrm{mg} / \mathrm{L}$ compared to $\sim 80 \mathrm{mg} / \mathrm{L}$ used in Huang and Wilson's experiments. The total time for the CGA flotation was less than 3 minutes.

The failure of the CGA flotation to remove any appreciable amount of copper sulfide precipitate from the Wyoming drainage water sample was unexpected. A possible explanation involves the probability that a given bubble will encounter, and potentially trap, a significant number of precipitate particles on its path to the surface. At lower concentrations this probability is reduced. The small volume of CGA and short contact time used in the experiments may not have provided a significant number of trapping encounters between CGA bubbles and precipitate particles. The drainage water also contained ions and particles not present in the prepared solution; one or more of these may have inhibited the flotation of the CuS precipitate from the mixture.

The majority of the experiments using the Wyoming drainage water sample involved precipitation of the copper as the hydroxide/oxide followed by flotation with CGA. The open markers in Figure 2 show the effect of increasing $\mathrm{pH}$ on copper removal from a prepared solution with an initial copper concentration of $\sim 3.5 \mathrm{mg} / \mathrm{L}$. CGA prepared from DDS was used for the flotation. At pH 5.8 very little copper was removed from the solution while about $73 \%$ of the copper was removed at $\mathrm{pH} \sim 10.4$.

The solid markers in Figure 2 show copper removal from the prepared solution by adsorbing colloid flotation using DDS CGA. For these experiments $\mathrm{FeCl}_{3}$ solution was added to provide an initial $\mathrm{Fe}^{3+}$ concentration of $10 \mathrm{mg} / \mathrm{L}$. The added $\mathrm{Fe}^{3+}$ precipitates as $\mathrm{Fe}(\mathrm{OH})_{3}$, forming a floc that adsorbs and/or coprecipitates with the copper. The floc, with the trapped contaminant, is then floated from the mixture. The use of the $\mathrm{Fe}(\mathrm{OH})_{3}$ coprecipitate improved copper removal significantly with more than $80 \%$ removed at $\mathrm{pH} 6.4$, and $97 \%$ removed at $\mathrm{pH}$ 10.4 .

Figure 3 shows the effect of increasing $\mathrm{Fe}^{3+}$ concentration on copper removal from the prepared solution (solid markers) and from the Wyoming drainage water sample (open markers). Experiments using the Wyoming drainage water had an average $\mathrm{pH}$ of 10.7 before flotation; those using the prepared solution had an average $\mathrm{pH}$ of 9.7. For both of the samples, increasing the $\mathrm{Fe}^{3+}$ concentration improved the separation efficiency within the range tested. In all cases the flotation removed more copper from the prepared solution than from the actual drainage water sample.

The effectiveness of water treatment is usually evaluated in terms of residual concentration of the contaminant remaining in the cleaned water. Figure 4 shows the effect of increasing $\mathrm{Fe}^{3+}$ concentration on residual copper levels in the flotation effluent. Even though the initial copper concentration was somewhat higher in the prepared solution $(3.5 \mathrm{mg} / \mathrm{L})$ compared to the drainage water $(1.7 \mathrm{mg} / \mathrm{L})$, flotation of the prepared solution yielded lower residual copper levels. It appears that some constituent of the drainage sample tends to partially inhibit copper 
flotation. This effect may be due to the presence of other multivalent ions competing for adsorption sites.

Figure 5 shows the effect of $\mathrm{pH}$ on residual copper concentration for adsorbing colloid flotation using DDS CGA. Open markers in the figure represent results of experiments using the Wyoming drainage water sample with $10-\mathrm{mg} / \mathrm{L} \mathrm{Fe}^{3+}$ added. Solid markers represent experiments using the prepared solution (above) with $18-\mathrm{mg} / \mathrm{L} \mathrm{Fe}^{3+}$ added.

Figure 6 shows the effect of $\mathrm{pH}$ on residual copper concentration for a series of eighteen experiments with the Wyoming drainage water sample. The experiments used adsorbing colloid flotation with $10-\mathrm{mg} / \mathrm{L} \mathrm{Fe}^{3+}$ added. The flotation used CGA prepared from DDS. In these experiments $\sim 5 \mathrm{~mL}$ of CGA was used to treat $100 \mathrm{~mL}$ of drainage water.

The CGA from the generator used in these experiments contained $\sim 50 \%$ entrained air. Therefore, $\sim 2.5 \mathrm{~mL}$ of surfactant solution was used to treat $100 \mathrm{~mL}$ of liquid to give the results shown in Figure 6. The surfactant solution contained 333-mg/L DDS; thus, with respect to the column liquid treated, the surfactant concentration was $\sim 8.3 \mathrm{mg} / \mathrm{L}$. Figure 7 shows the effect on residual copper concentration when a prepared copper solution was treated with increasing volumes of CGA. For these experiments the $\mathrm{pH}$ was set at 10 and $18-\mathrm{mg} / \mathrm{L} \mathrm{Fe}^{3+}$ was added. The initial copper concentration of the prepared solution was $3.5 \mathrm{mg} / \mathrm{L}$. The CGA volumes shown in Figure 7 represent surfactant concentrations with respect to the liquid treated, ranging from $\sim 2-$ $12 \mathrm{mg} / \mathrm{L}$.

With a surfactant concentration equivalent to only $2 \mathrm{mg} / \mathrm{L}$ of column liquid, CGA flotation removed more than $80 \%$ of the copper from this solution. Increasing the volume of CGA used to treat the column liquid increased copper removal to $93 \%$ with a surfactant concentration equivalent to $11.5 \mathrm{mg} / \mathrm{L}$ of column liquid.

In the final experiments using the Wyoming drainage water sample $\mathrm{FeCl}_{3}$ solution was added to provide an initial $\mathrm{Fe}^{3+}$ concentration of $50 \mathrm{mg} / \mathrm{L} .1 \mathrm{~N} \mathrm{NaOH}$ solution was added to increase the $\mathrm{pH}$ to 11.25 and the mixture was treated by flotation with $\sim 5 \mathrm{~mL}$ of DDS CGA. The experiment was repeated four times, yielding residual copper concentrations of $0.04,0.02,0.00$, and $0.02 \mathrm{mg} / \mathrm{L}$. The average residual copper concentration for these four experiments was 0.02 $\mathrm{mg} / \mathrm{L}$, representing the removal of $99.2 \%$ of the copper originally dissolved in the drainage sample.

\section{Experiments Using the Colorado Drainage Sample}

In the initial experiments using the Colorado drainage water sample, contaminant metals were precipitated by the addition of $\mathrm{NaOH}$ solution. Figure 8 shows the effect of increasing $\mathrm{pH}$ on the removal of dissolved iron, copper, cadmium, and zinc. For these experiments the metallic 
precipitates were floated using CGA prepared from a solution containing $333 \mathrm{mg} / \mathrm{L}$ of Triton X100 surfactant.

Figure 9 shows the effect of added sulfide on the removal of iron, copper, cadmium, and zinc from the Colorado sample. For these experiments the drainage water sample was treated by the addition of $\mathrm{NaOH}$ to adjust the $\mathrm{pH}$ and sodium sulfide to provide an initial sulfide concentration of $42 \mathrm{mg} / \mathrm{L}$. After the addition of precipitating reagents the mixture was transferred to the column and floated with X-100 CGA as described above. The resulting foam was removed from the column and the liquid was treated a second time using X-100 CGA.

Figure 10 shows the effect of $\mathrm{pH}$ on the removal of iron, copper, cadmium, and zinc from the Colorado drainage sample when sulfide was added following $\mathrm{NaOH}$ precipitation and CGA flotation. For these experiments the drainage water sample was initially treated by the addition of $\mathrm{NaOH}$ solution and subsequently floated with X-100 CGA. The liquid was then drained from the column and returned to the mixer where sodium sulfide solution was added to provide an initial sulfide concentration of $10 \mathrm{mg} / \mathrm{L}$. Following the addition of the sulfide solution, the resulting mixture was returned to the column and floated a second time using X-100 CGA.

Selected precipitations were duplicated and the resulting mixtures were transferred to graduated cylinders where they stood undisturbed for 12 hours while the precipitates settled. These experiments were conducted to provide a comparison, in terms of metals removal, between CGA flotation and gravity separation. The experiments showed very similar residual metals concentrations for the two methods, indicating that CGA flotation is as effective as gravity settling for the removal of metallic precipitates.

Economics is an important consideration in the selection of water-treatment technologies. To be commercially viable, CGA flotation must provide a low-cost alternative to available methods for concentrating precipitates. Lab-scale experiments generally do not provide sufficient data with which to prepare accurate estimations of overall process economics. These experiments can, however, provide a fairly accurate estimate of reagent consumption. Reagent consumption will be a major factor in determining operating costs for CGA flotation. Therefore, this factor can be used to provide a reasonable basis for a preliminary economic comparison between CGA flotation and gravity separation of precipitates.

Figure 11 shows the relationship between surfactant consumption and metals removal for a series of CGA flotation experiments. Surfactant consumption, in milligrams of surfactant per liter of liquid treated, is shown on the X-axis. The $4-20 \mathrm{mg} / \mathrm{L}$ range shown on the chart is equivalent to $0.033-0.167$ pounds of surfactant per thousand gallons treated. At an estimated cost of $\$ 2.50$ per pound, surfactant costs for CGA flotation would amount to $\$ 0.08-\$ 0.41$ per thousand gallons treated. 
In the experiments referred to above, $\mathrm{NaOH}$ solution was added to the drainage water sample to increase the $\mathrm{pH}$ to 5.9. The resulting mixture was floated with a measured volume of $\mathrm{X}-100$ CGA. The liquid was then drained from the column and returned to the mixer where sodium sulfide solution was added to provide an initial sulfide concentration of $9.3 \mathrm{mg} / \mathrm{L}$. Following the addition of the sulfide solution, the mixture was returned to the column and floated using another measured volume of X-100 CGA. Equal volumes of CGA were used for both flotation steps.

The experiments probably did not represent optimum usage of the CGA. It is quite possible, for example, that a smaller volume of CGA could have been used for the second flotation. Optimization of CGA usage should provide lower surfactant costs than those estimated from this series of experiments. The cost estimate given above also did not include an allowance for surfactant recovery and reuse. In actual practice much, if not most, of the surfactant would be recovered from the draining foam and returned to the process. When allowances are made for optimization of CGA usage and surfactant recovery it is probable that the surfactant cost, as estimated from these experiments, can be reduced significantly.

The use of less expensive surfactants could also reduce the cost of CGA flotation. The sodium salt of oleic acid (sodium oleate) is a relatively inexpensive surfactant that can be an effective collector for flotation of $\mathrm{Fe}(\mathrm{OH})_{3}$ precipitates. Initial attempts to prepare CGA from a $330-\mathrm{mg} / \mathrm{L}$ solution of sodium oleate were not successful. Only a small amount of air was entrained in the generator, and the resulting bubbles were rather large and unstable. The addition of $\sim 50 \mathrm{mg} / \mathrm{L}$ of SF5100 surfactant provided a stable CGA with $>50 \%$ entrained air. Flotation with the sodium oleate/SF5100 CGA was very effective. The use of CGA prepared from sodium oleate and an inexpensive frother could reduce the surfactant costs estimated above by as much as $50 \%$.

The cost of CGA flotation will also be influenced by discharge limitations in effect at the various sites. As shown in Figure 11, the first volume of CGA removes the bulk of the precipitates. Subsequent volumes remove less as the amount of precipitate suspended in the liquid decreases. In cases where removal of $90 \%$ of the precipitate would meet discharge requirements, treatment costs could be very low. Costs increase for higher removal efficiencies.

Refinement of the method should provide lower surfactant costs than those estimated based on these preliminary experiments. However, even at the levels predicted by the experiments, the cost of CGA separation should compare favorably with that of gravity separation. In practice, chemicals are frequently employed to improve sludge settling characteristics in gravity separations (Schwoyer, 1981). The cost of chemicals used in gravity separation would offset surfactant costs for the CGA flotation. This offset would reduce or eliminate the advantage (in terms of reagent costs) for gravity settling. 
Based on the estimates from lab-scale experiments (and assuming $\$ 2.50 / \mathrm{lb}$ surfactant cost and contaminant concentrations similar to the Colorado sample), surfactant costs for treatment of a 200-gallon-per-minute flow would range from $\$ 8,500-\$ 43,000$ per year depending on discharge limitation requirements. This additional cost would be only a fraction of the total annual treatment costs including capital, operation, maintenance, and sludge disposal for a facility of this size. Larger-scale experiments are needed to provide a more accurate assessment of the cost of mine water treatment using CGA flotation. However, within the limits of certainty imposed by the small scale of these experiments, it appears that CGA flotation will be economically competitive with other available treatment technologies for drainages similar to the Colorado sample.

A series of experiments was conducted that compared foam/sludge volumes from CGA flotation and simple gravity sedimentation. For a typical experiment, precipitating reagents were added to a measured volume of drainage water with continuous stirring. After stirring until the $\mathrm{pH}$ had stabilized, the mixture was split into two equal volumes. One volume was poured into an Imhoff settling cone and allowed to settle. The remaining volume was poured into a flotation column and treated with CGA. Sludge/foam volumes were recorded at intervals as the sludge settled to the bottom of the cone and the foam drained and collapsed on the surface of the liquid in the column.

Figures 12 and 13 show sludge/foam volumes for sedimentation/CGA flotation at $\mathrm{pH} 6.1$ and $\mathrm{pH}$ 6.7, respectively. CGA was prepared from a solution containing $330 \mathrm{mg} / \mathrm{L}$ of Triton X100 surfactant. The sharper separation shown in Figure 14 was obtained when the sample was precipitated at $\mathrm{pH} 6.4$ and floated using CGA prepared from a solution containing $330 \mathrm{mg} / \mathrm{L}$ of Betz SF 5100 surfactant. In experiments with the Colorado drainage sample, CGA flotation using this surfactant routinely concentrated precipitates into $\sim 10 \%$ of the original volume in 10 minutes or less. In a number of the experiments concentrate volume was reduced to $\sim 10 \%$ of the original volume in about 2 minutes.

Samples of foam continued to drain after being removed from the column. This additional drainage further concentrated the precipitates into $\sim 6 \%$ of the original volume. The time required for foam drainage varied significantly, from 1 or 2 minutes to nearly 40 minutes between experiments. The inconsistent drainage times may have resulted from some variation in technique when the foam was removed from the surface of the liquid by suction with a pipette. The pipette apparently functioned more effectively as a foam breaker in some experiments. More effective foam breaking in the pipette would, presumably, allow for faster drainage of the foam. For an actual process using an efficient foam breaker, it is probable that the time required for foam drainage would be closer to the lower values obtained in these experiments.

The solid precipitate content of the foam from CGA flotation and the sludge from sedimentation were proportionate to their relative volumes with respect to the liquid treated. After treatment at $\mathrm{pH} 6.5$ solid precipitate contents were $0.37 \mathrm{wt} \%$ and $0.13 \mathrm{wt} \%$ for the foam 
and sludge, respectively. Secondary drainage, as described above, further concentrated the foam, increasing the final solids content to $\sim 0.62 \mathrm{wt} \%$.

Precipitates concentrated as foams or sludges typically undergo additional dewatering steps before their final disposal. Whether concentrated by sedimentation or flotation, ultimately the disposal volume is largely dependent on the efficiency of the dewatering step. The use of CGA flotation to concentrate precipitates can significantly reduce the amount of liquid that must be removed in the dewatering step. The reduced liquid loading afforded by CGA flotation should allow for a reduction in dewatering costs.

Figure 15 shows a preliminary flow sheet for a $100-\mathrm{L} / \mathrm{min}$ process demonstration unit for CGA flotation of the Colorado mine drainage water. The drainage flows into a mixer where precipitating reagents are added to adjust the $\mathrm{pH}$ to 6.5 and provide $10 \mathrm{mg} / \mathrm{L}$ of sulfide. The mixture then flows into the bottom of the flotation column where it contacts a rising swarm of CGA bubbles. The bubbles are skimmed from the top of the column and deposited in the foam drain vessel. The drained foam then goes to the filter for final dewatering. A portion of the water from the foam draining and dewatering is recycled to the CGA generator. The remainder is mixed with the cleaned water from the column and discharged.

\section{Experiments Using the South Dakota Drainage Sample}

CGA treatment of the South Dakota drainage sample was not effective. The method did not provide a significant reduction in sludge/foam volume when compared to simple sedimentation, and none of the surfactants that were tried produced stable foams. In most of the experiments the foam volume was $>25 \%$ of the original sample volume, and some of the foam typically began to sink before the flotation was completed. Metals were precipitated using either $\mathrm{Ca}(\mathrm{OH})_{2}$ or $\mathrm{NaOH}$ over a $\mathrm{pH}$ range of $6-7$. Neither base provided any significant advantage in terms of the CGA flotation.

The inability to effectively float this sample was probably due to the very high concentration of suspended solids in the precipitated sample. The untreated sample contained more than $8,800 \mathrm{mg} / \mathrm{L}$ total dissolved solids. Precipitation of these dissolved solids results in a concentration of suspended solids considerably greater than the maximum limit for effective treatment by flotation processes. This possible explanation was supported by a series of experiments in which the sample was diluted with three volumes of water. In these experiments the CGA flotation was successful, but because of the increase in treatment volume, no actual reduction in concentrate volume was realized.

\section{SUMMARY AND CONCLUSIONS}

Experiments were conducted that used emulsions of microbubbles (CGA) for flotation of metallic precipitates from three mine drainage water samples and a prepared solution. Samples 
of actual drainage waters were collected from an abandoned copper mine in Wyoming, an abandoned gold mine in Colorado, and an active gold mine in South Dakota. The collected samples represented a wide variety of mine drainage water problems. The experiments used common industrial precipitating reagents followed by flotation with CGA prepared from a variety of surfactants. The experimental results were evaluated in terms of metals concentration reduction, reagent consumption, and concentrate volume.

Adsorbing colloid flotation using CGA proved to be only partially effective for the removal of copper from the Wyoming sample. Flotation experiments using $\mathrm{Fe}(\mathrm{OH})_{3}$ as a coprecipitate (adsorbing colloid) reduced copper levels in the cleaned water by approximately $90 \%$ over most of the alkaline range up to $\mathrm{pH} \sim 10$. In experiments where the $\mathrm{pH}$ was increased to 11.25 , residual copper levels lower than $0.02 \mathrm{mg} / \mathrm{L}$ ( $>99 \%$ copper removal) were achieved. The separation was quite rapid, very little surfactant was required, and the volume of foam containing the concentrated copper precipitate was small. The laboratory experiments failed to achieve residual copper levels at or below the $0.15 \mathrm{mg} / \mathrm{L}$ specified for treatment of this drainage, except when the $\mathrm{pH}$ was increased above 11 . However, it seems likely that with some additional refinement, the technique could meet this stringent requirement at a somewhat lower $\mathrm{pH}$.

For the Wyoming copper mine drainage, adsorbing colloid flotation using CGA does not appear to represent a practical alternative to currently available technologies. In terms of metals removal the process did not consistently meet the discharge requirements for this drainage without a fairly drastic increase in $\mathrm{pH}$. While this problem may have been solvable, the process did not appear to be economically competitive when compared with a simple ion exchange system that could also treat the drainage effectively. However, when compared to the sedimentation process used as an experimental control, CGA flotation was very effective, providing significant reductions in both separation time and sludge volume.

Chemical precipitation with lime followed by CGA was very effective for the removal of dissolved metals from the Colorado drainage sample. Metals separation was rapid, little surfactant was needed, and the concentrate volume was small. Residual metals concentration was low and experimental conditions could be adjusted to consistently meet the discharge limitations for this drainage. For this sample the method provided the required metals removal with low reagent consumption and significantly better concentration (lower sludge volume) when compared to sedimentation.

CGA flotation was not effective for treatment of the South Dakota drainage water sample. None of the combinations of precipitating reagents and CGA surfactants tried in this study provided a significant concentration of metallic contaminants. The author believes that the ionic strength of this drainage is simply too high for effective flotation with the low surfactant concentrations that are typical of the CGA flotation process. 
Of the three samples selected for these experiments, only the Colorado drainage sample was effectively treated by CGA flotation in accordance with the evaluation criteria used for this study. For the Wyoming copper mine drainage sample with its low initial metals concentrations and strict discharge limitations, difficulty was encountered in meeting the discharge limitation and the process did not appear to be economically competitive with simple ion exchange. For the South Dakota sample with very high dissolved metals concentration, CGA flotation seemed to be inhibited by the high ionic strength and did not provide a significant concentration of contaminant metals. The high sludge volumes associated with experiments using this sample would make the process impractical for treatment of this drainage.

The results of this preliminary study strongly indicate that the viability of CGA flotation as a method for cleaning mine drainage waters is dependent on the initial concentration of dissolved metals. For very low dissolved metals concentrations the CGA flotation is more reagent intensive than some other available methods, while little separation was realized for the sample with a very high concentration of dissolved metals. For the sample with intermediate dissolved metals concentration the separation was quite effective. In terms of residual metals content, reagent consumption, and wet sludge volume CGA flotation appears to be competitive with, and potentially superior to, existing technologies that are available for the treatment of this type of drainage.

CGA flotation does not represent a "silver bullet" that can solve all of the wide variety of mine drainage problems that exist in the western United States. However, for some types of drainage water, the use of this technology may help to extend practical treatment capabilities to more remote locations. For drainages similar to the one from which the Colorado sample was obtained, the use of this method could substantially reduce the overall size and capital cost of necessary treatment facilities. The size of the sludge separation operation can be reduced by taking advantage of the low retention time characteristic of CGA flotation. In addition, the relatively dry foam concentrate from the flotation process can reduce treatment volume, and hence size for expensive final dewatering operations. The possibility of modular construction and a very small process footprint both recommend this process as a possible alternative to sedimentation-type processes, especially for remote locations where construction costs can be very high. 


\section{REFERENCES}

Adrian Brown Consultants, Inc., 1994, Ferris-Haggarty Mine Drainage Study, Adrian Brown Consultants, Inc., Littleton, CO, 36.

Bhattacharyya, D., A. Jumawan, Jr., and R. Grieves, 1979, Separation of Toxic Heavy Metals by Sulfide Precipitation, Separation Science and Technology, 14(5): 363-374.

Clarke, A. N., and D. J. Wilson, 1983, Foam Flotation Theory and Applications, Marcel Dekker, Inc., New York , 17-27.

Choi, Sang-June, and S. Ihm, 1988, Removal of Cu(II) from Aqueous Solutions by the Foam Separation Techniques of Precipitate and Adsorbing Colloid Flotation, Separation Science and Technology, 23(4\&5): 363-374.

Feris, L. A., and J. Rubio, 1999, Dissolved Air Flotation at Low Saturation Pressures. Filtration and Separation, 36(9): 61-65.

Hach Water Analysis Handbook, second edition, 1992, Hach Co., Loveland CO, 656.

Huang, Shang-Da, and D. Wilson, 1976, Foam Separation of Mercury(II) and Cadmium (II) from Aqueous Systems. Separation Science, II(3): 215-222.

Kiuru, Heikki. J., 1990, Chemical Water and Waste Water Treatment, Hahn and Klute (Eds.) Springer-Verlag, New York, 169-180.

Knight Piesold LLC, May 12, 1997, Letter Report on Status of Geochemical Understanding of Ferris-Haggerty Waters, Knight Piesold LLC, Denver, CO, 8.

Larsen, Peter H., J. Shou, and L Ross, 1973, Chemical Treatment of Metal-bearing Mine Drainage. Water Pollution Control Federation Journal, 45(8): 1682.

Mckee, Jack W. and H. W. Wolfe, eds., 1963, Water Quality Criteria, The Resources Agency of California State Water Quality Control Board, Publication No. 3-A, 169-174.

Patterson, James W., 1985, Industrial Wastewater Treatment Technology, Butterworth Publishers, Stoneham MA, 91-102. 
Scamehorn, J. F., and J. H. Harwell, eds., 1989, Surfactant Based Separation Processes, Marcel Dekker, Inc., New York, 91-116.

\section{REFERENCES (continued)}

Schwoyer, W. H. K., ed., 1981, Polyelectrolytes for Water and Wastewater Treatment, CRC Press, Inc., Boca Raton, Florida, 159-170.

Shea, Paul T., and S. Barnett, 1979, Flotation Separation Using Microgas Dispersions, Separation Science and Technology, 14(9): 757-767.

Ulman, J. A., 1986, Control of Heavy Metal Discharge with Sodium Borohydride, in Thompson, R., ed., Trace Metal Removal from Aqueous Solution. Whitstable Litho Ltd., Whitstable, Kent, Great Britian, 173-196.

USEPA, 1993, Regional Environmental Monitoring and Assessment Program, EPA/625/R93/012, September 1993, U. S. Environmental Protection Agency, Office of Research and Development, Washington, D.C.

USEPA, 1973, Water Quality Criteria 1972, Report of the Committee on Water Quality Criteria, National Academy of Science, EPA-R3-73-033, U. S. Environmental Protection Agency, Washington, D.C.

USEPA, 1997, EPA's National Hardrock Mining Framework, EPA-833-B-97-003, U. S. Environmental Protection Agency, Office of Water, Washington, D.C. 


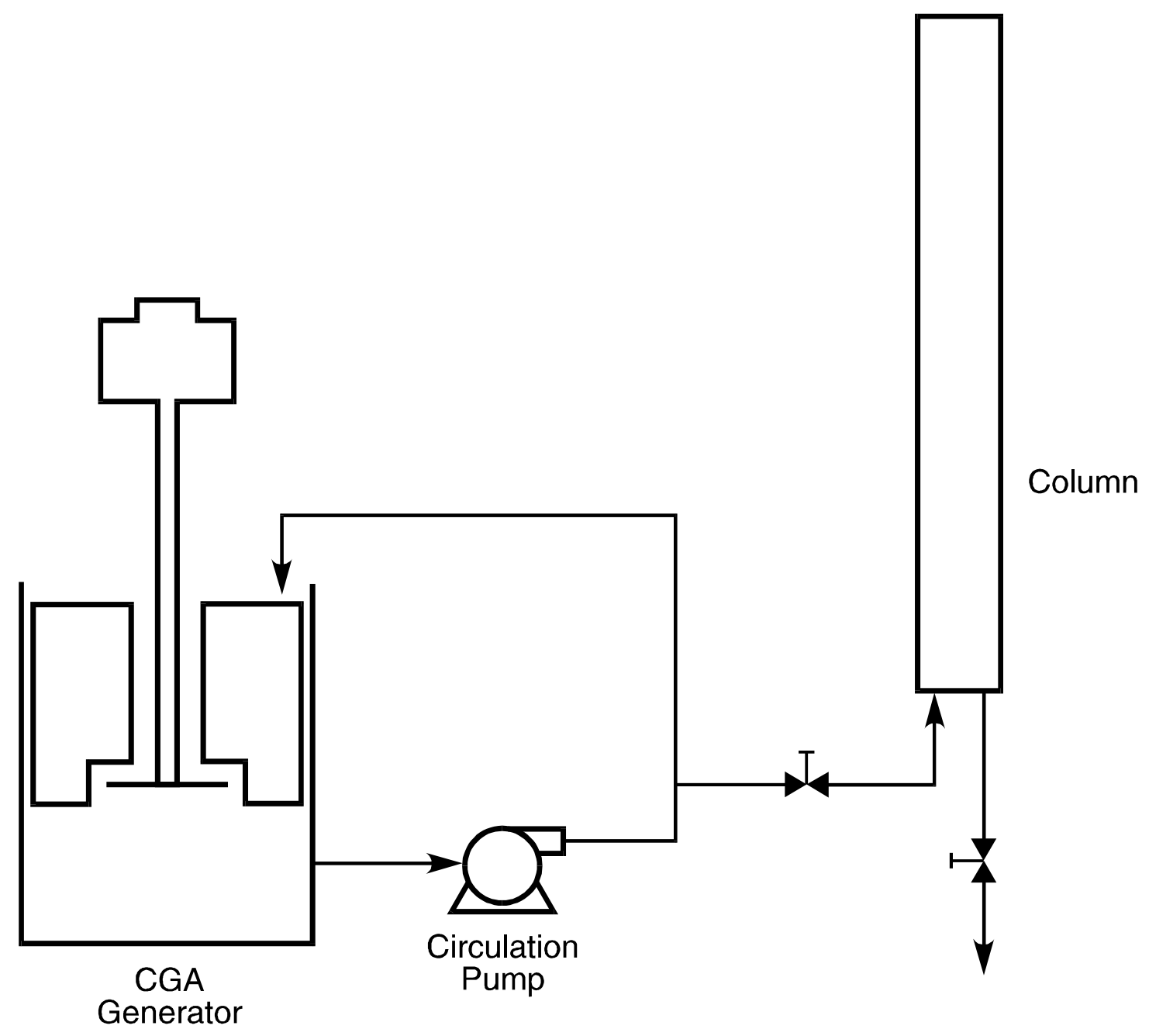

Figure 1. Schematic Diagram of the Experimental Apparatus 


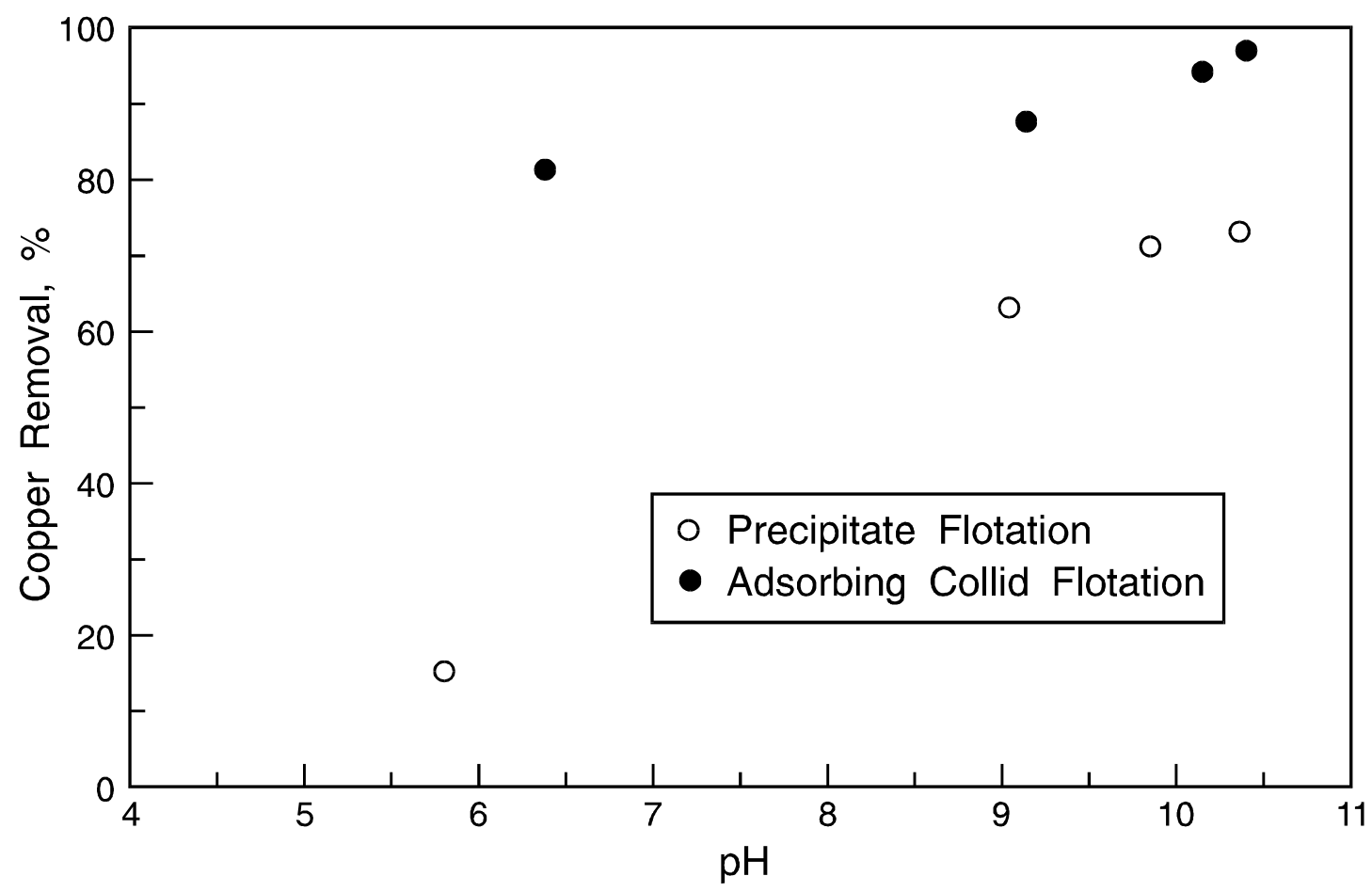

Figure 2. Effect of $\mathrm{pH}$ and Added Coprecipitate on Flotation of Copper Hydroxide Precipitate

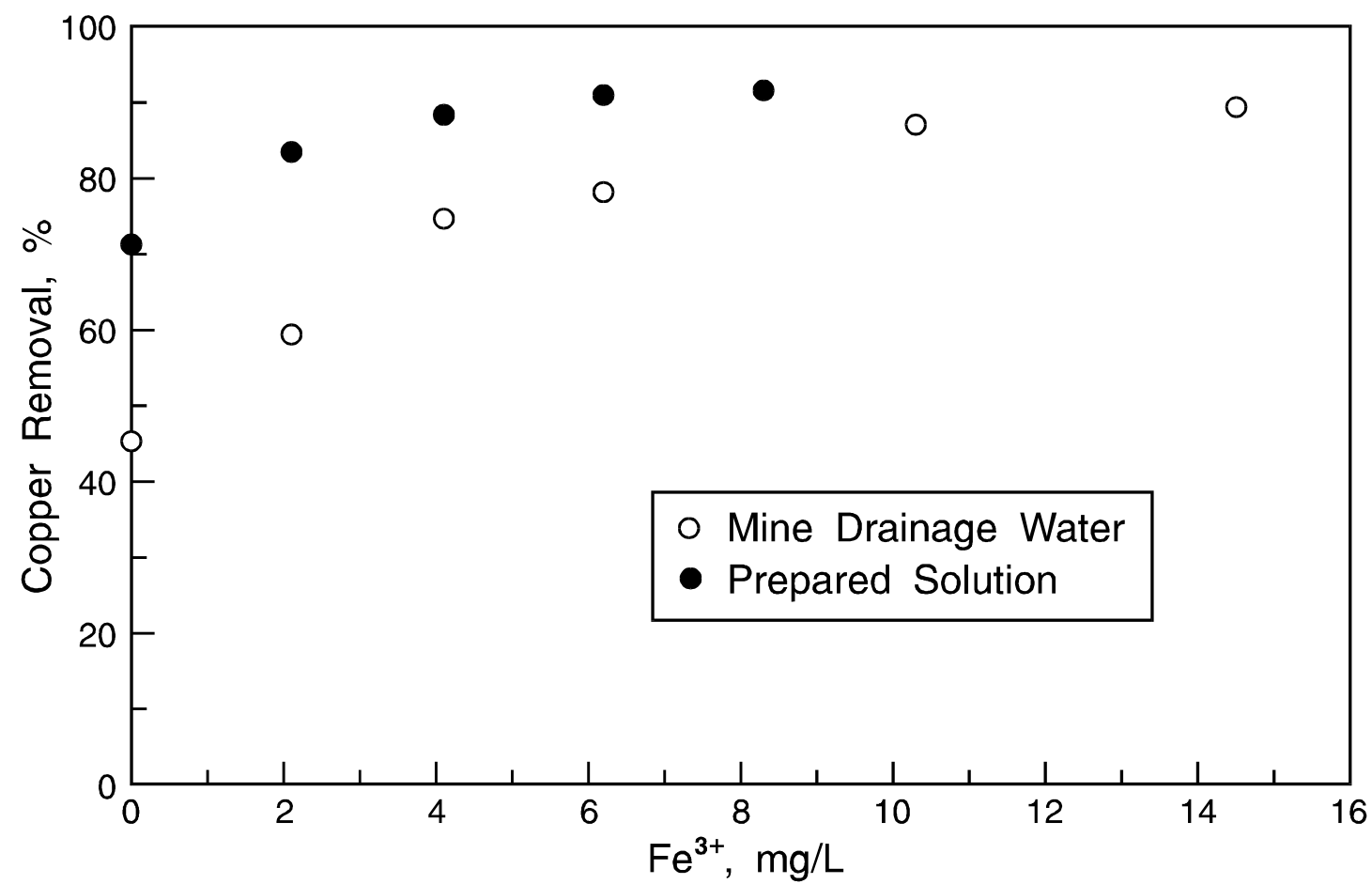

Figure 3. Effect of $\mathrm{Fe}^{3+}$ Concentration on Efficiency of Copper Removal by Adsorbing Colloid Flotation with $\mathrm{Fe}(\mathrm{OH})_{3}$ Coprecipitate 


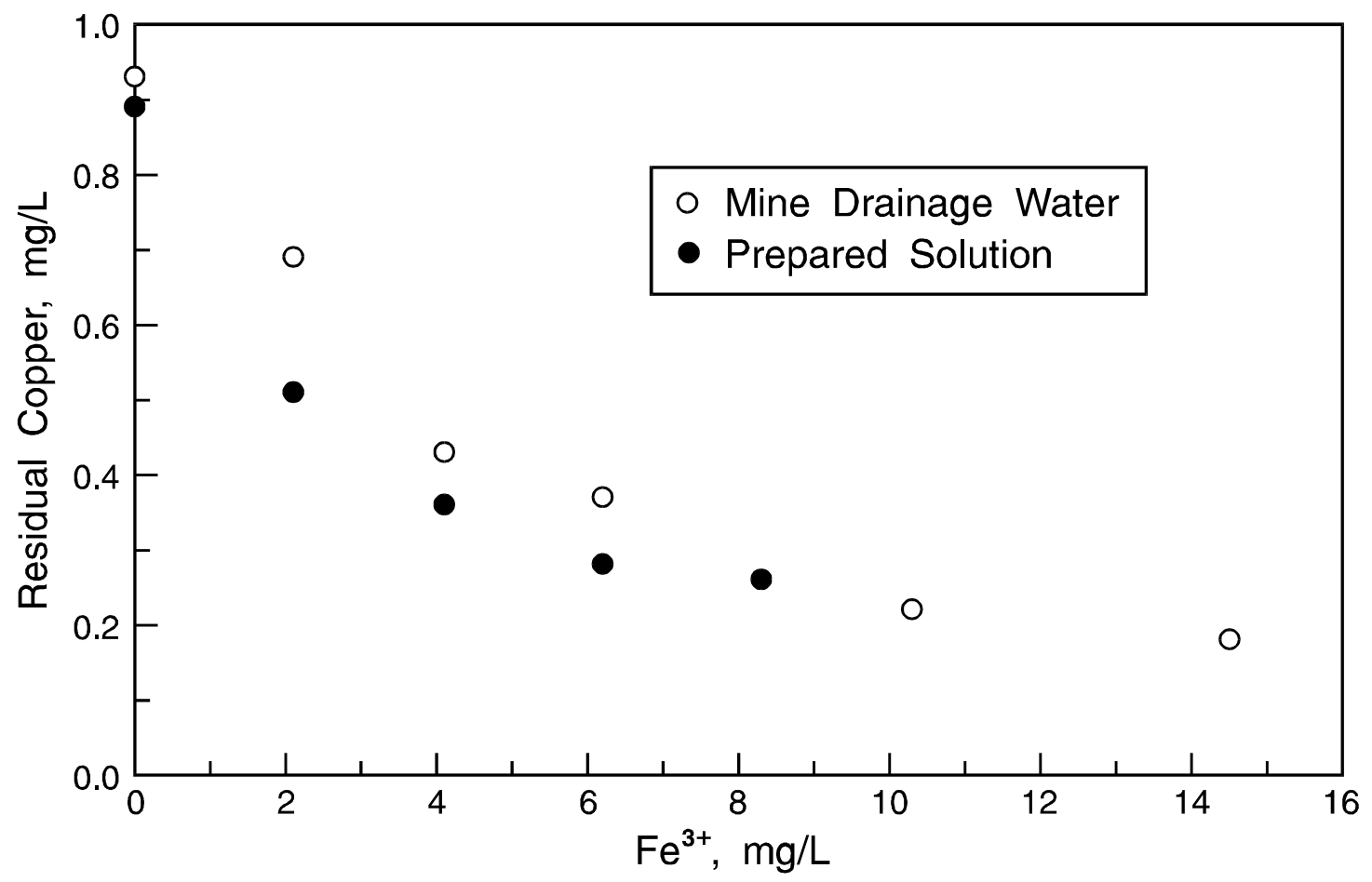

Figure 4. Effect of $\mathrm{Fe}^{3+}$ Concentration on Residual Copper Concentration After Adsorbing Colloid Flotation with $\mathrm{Fe}(\mathrm{OH})_{3}$ Coprecipitate

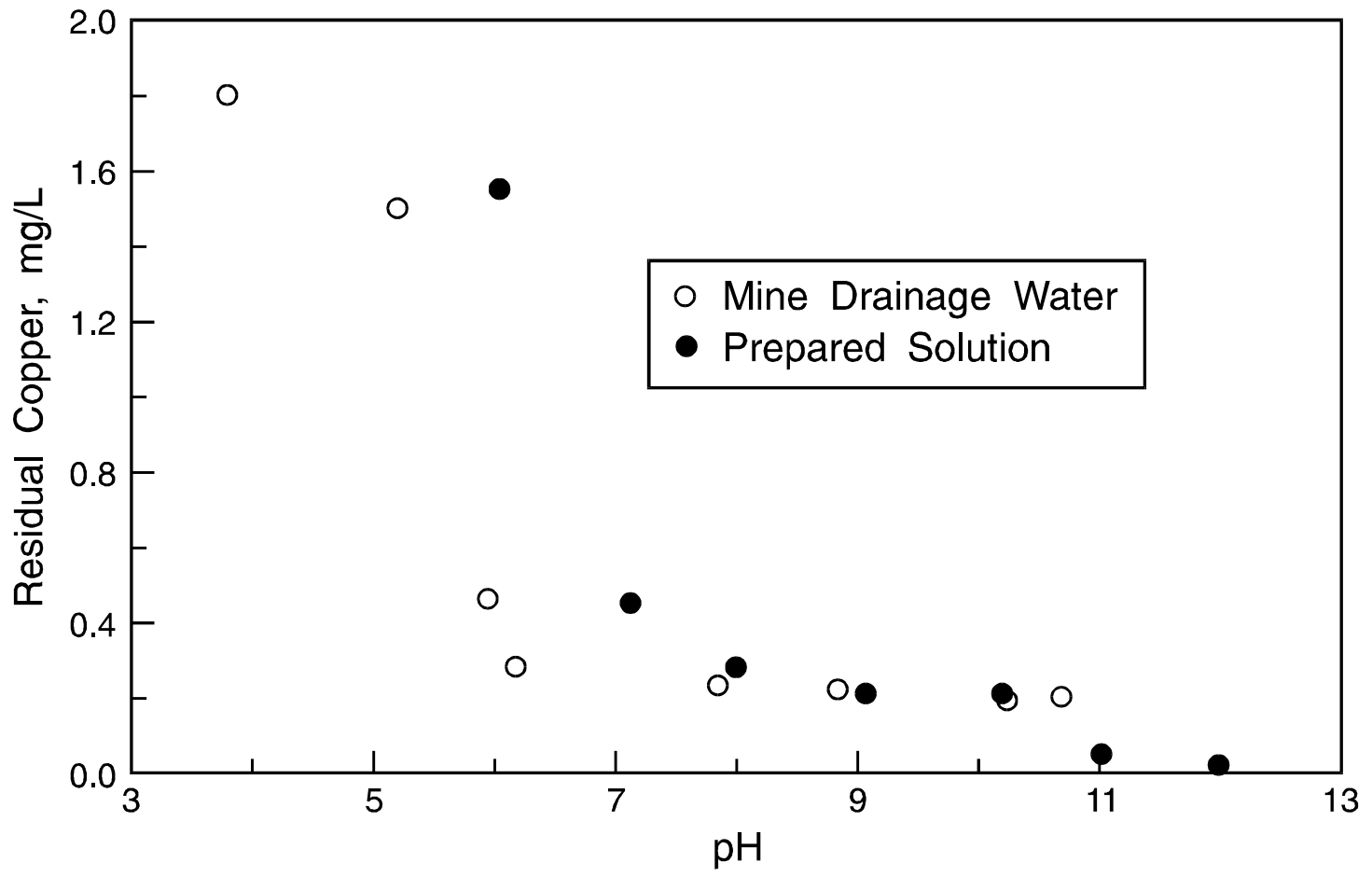

Figure 5. Effect of $\mathrm{pH}$ on Residual Copper Concentration After Adsorbing Colloid Flotation with $\mathrm{Fe}(\mathrm{OH})_{3}$ Coprecipitate 


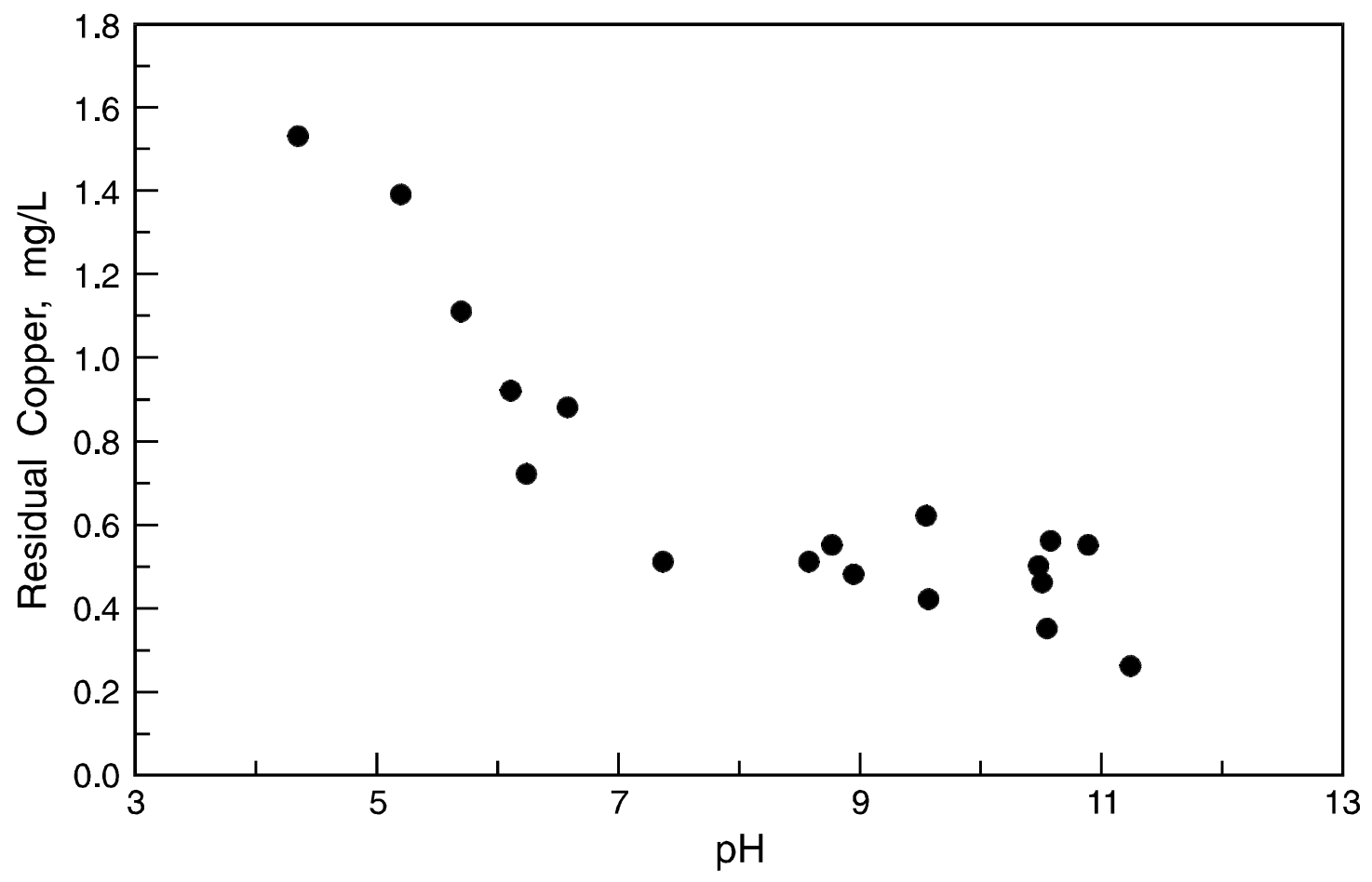

Figure 6. Residual Copper Concentrations from Eighteen Adsorbing Colloid Flotation Experiments Using the Wyoming Drainage Water

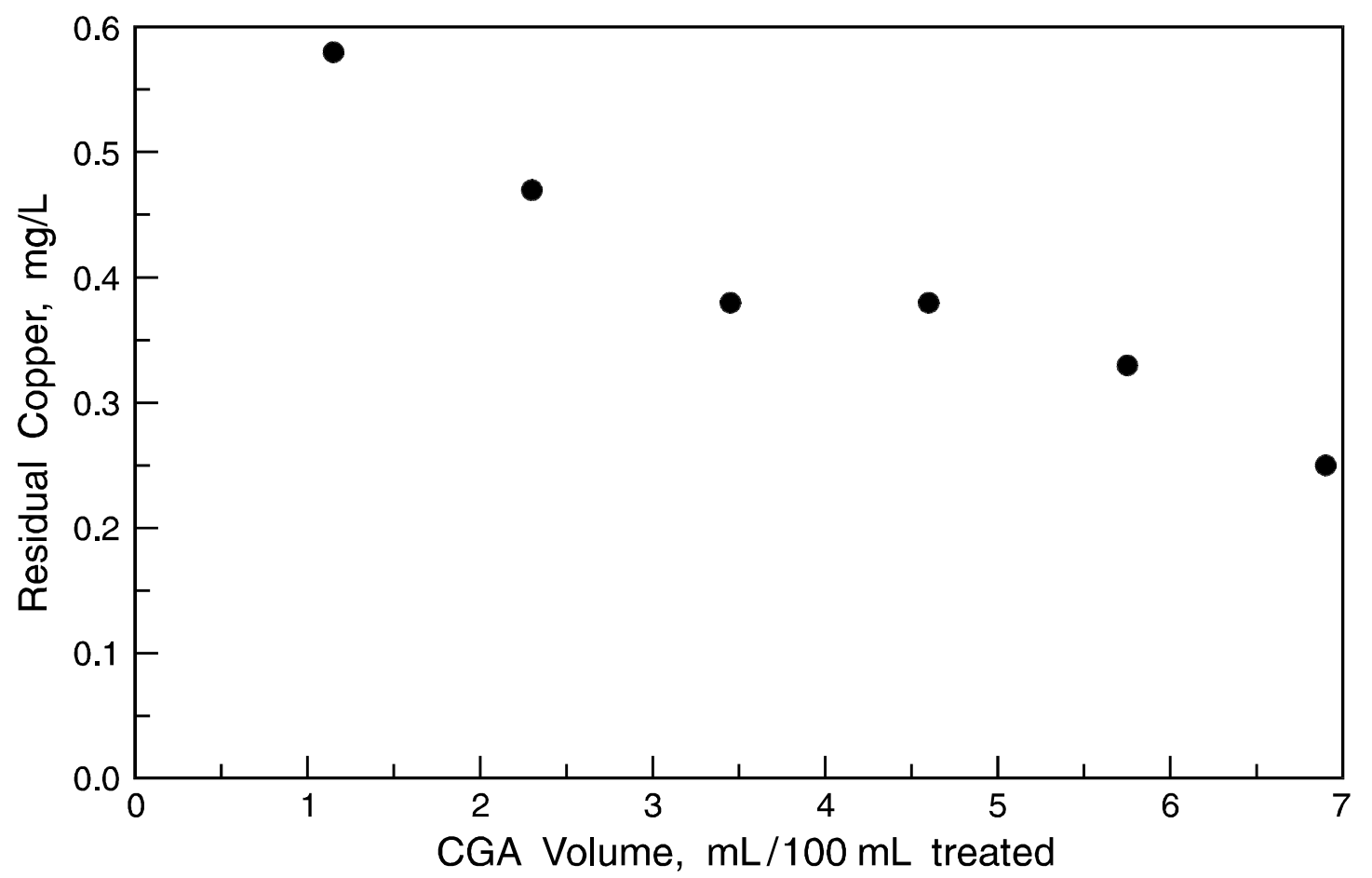

Figure 7. Effect of Increasing CGA Volume on Residual Copper Concentration 


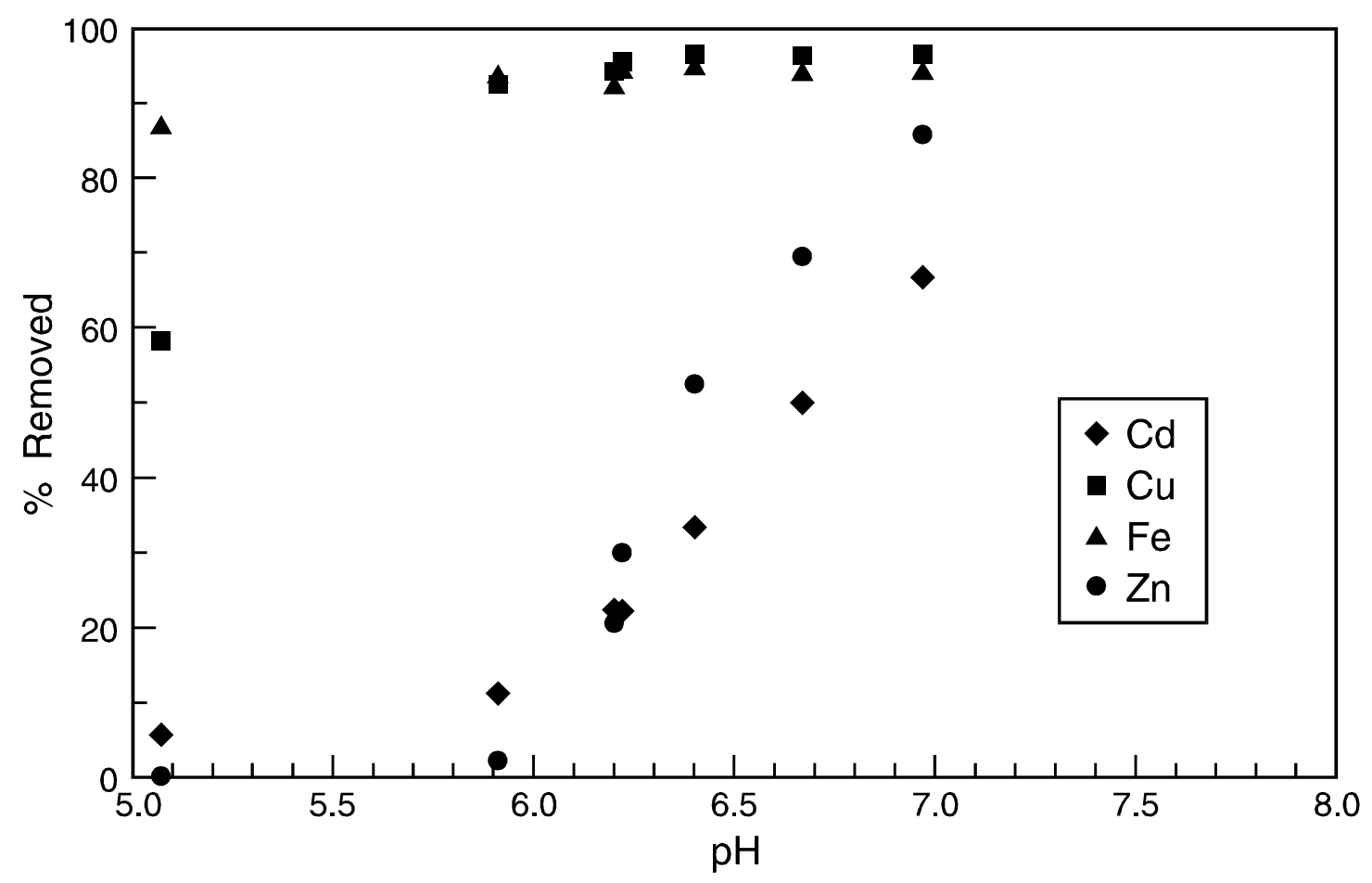

Figure 8. Effect of pH on Metals Removal from Colorado Drainage Sample

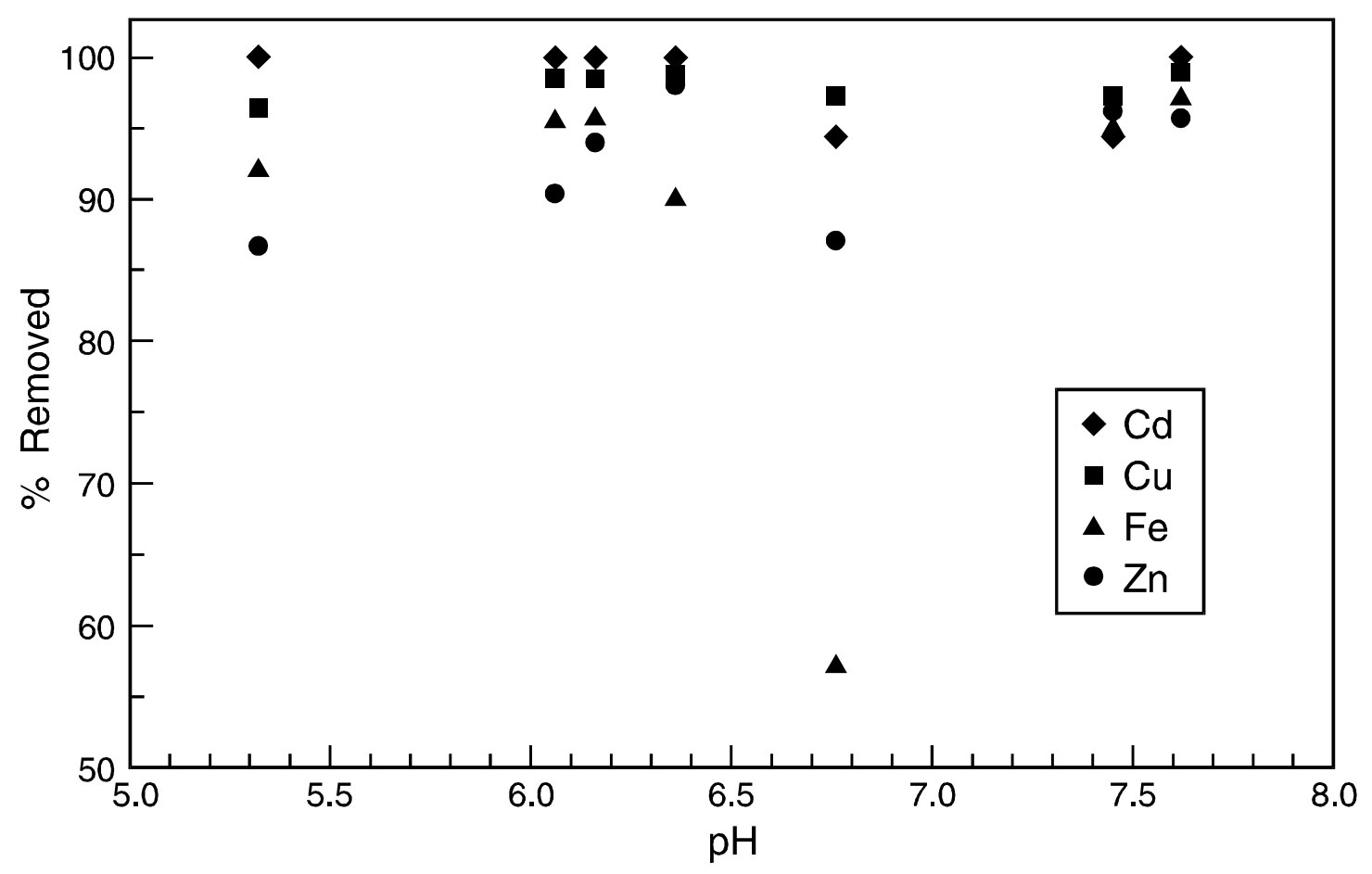

Figure 9. Effect of pH on Metals Removal from Colorado Drainage Sample with $42 \mathrm{mg} / \mathrm{L}$ Added Sulfide 


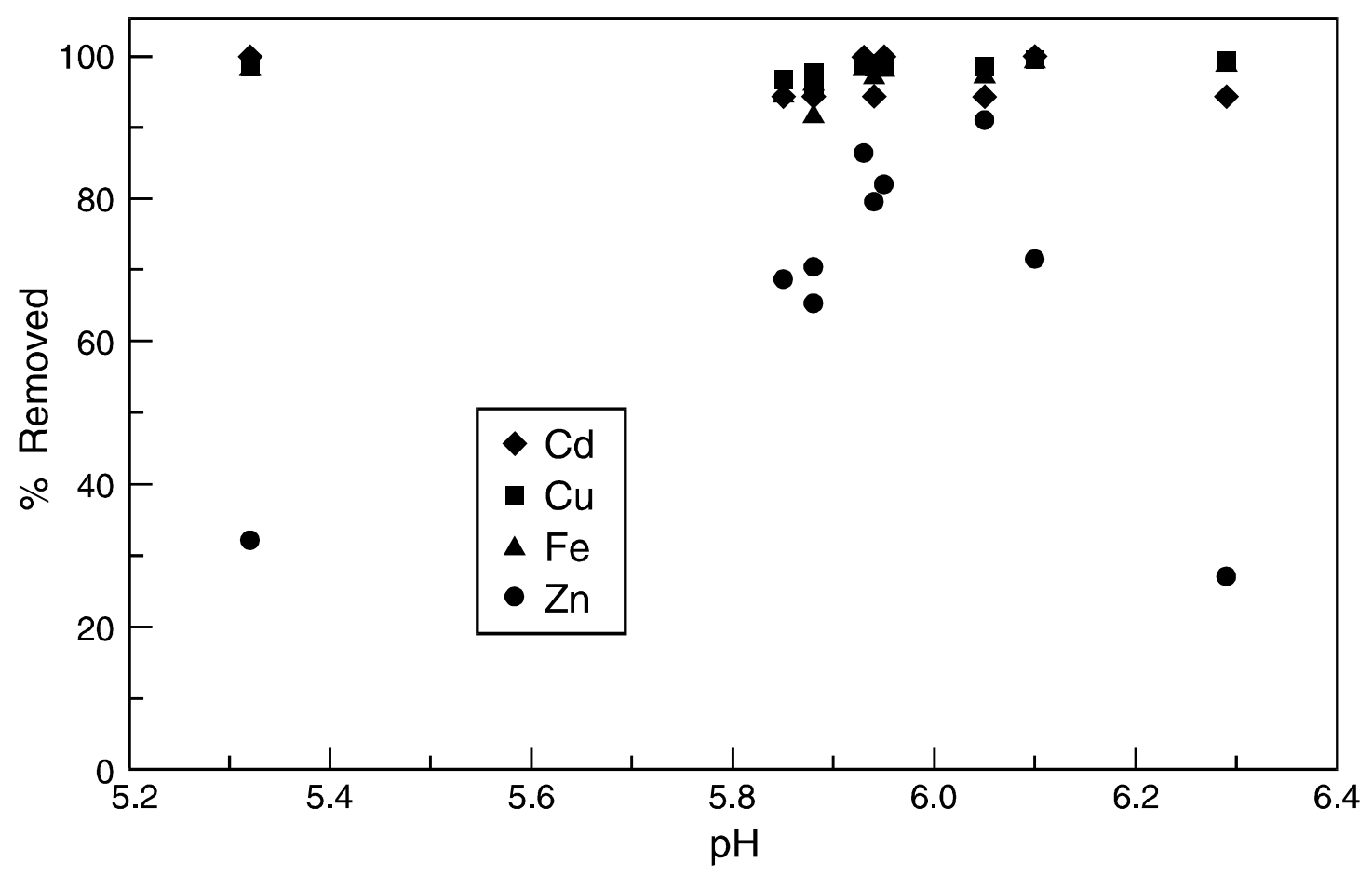

Figure 10. Effect of $\mathrm{pH}$ on Metals Removal from Colorado Drainage Sample, $10 \mathrm{mg} / \mathrm{L}$ Added Sulfide with Two-Step Flotation

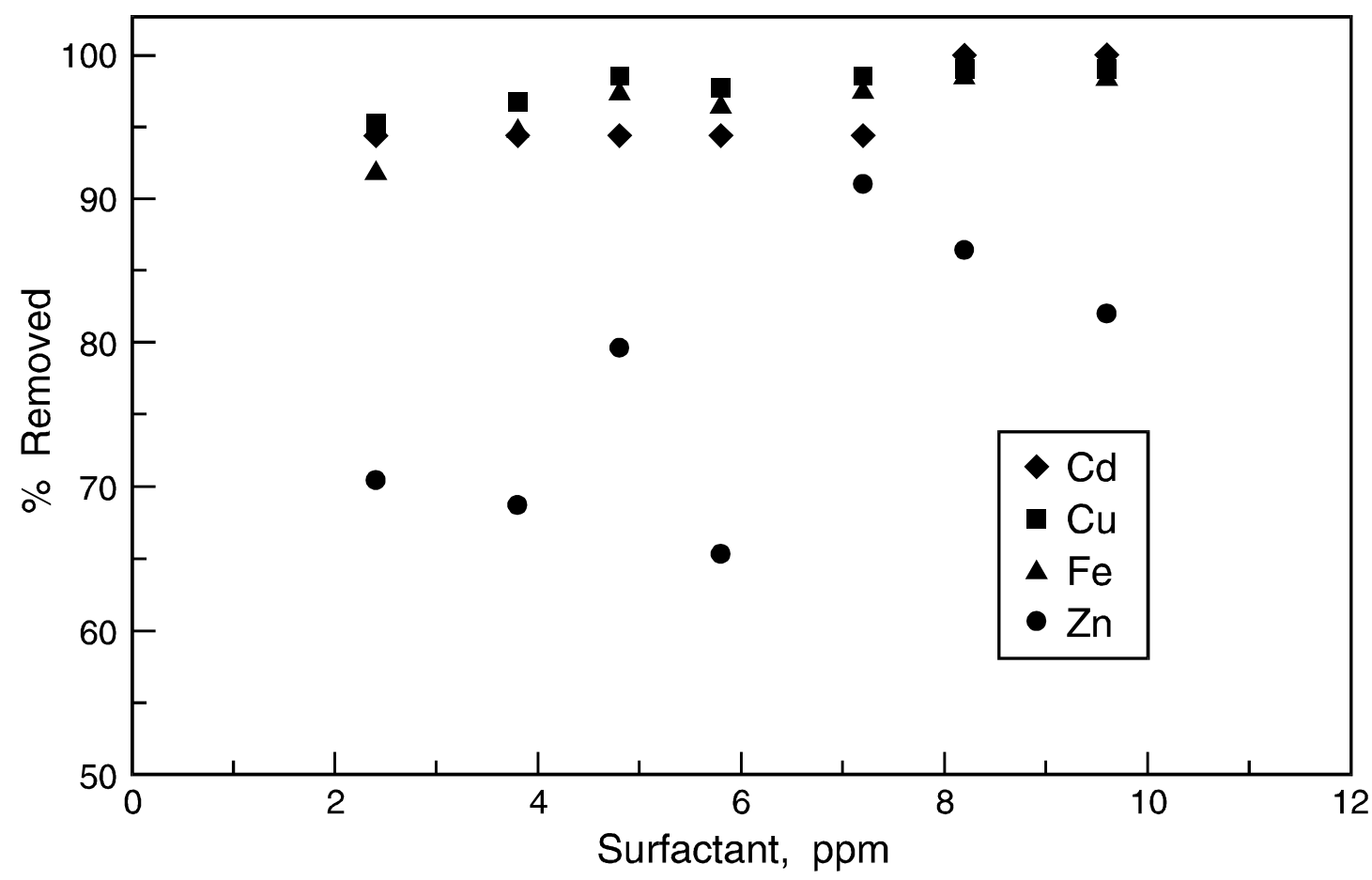

Figure 11. Metals Removal Versus Surfactant Consumption for Colorado Drainage Sample 


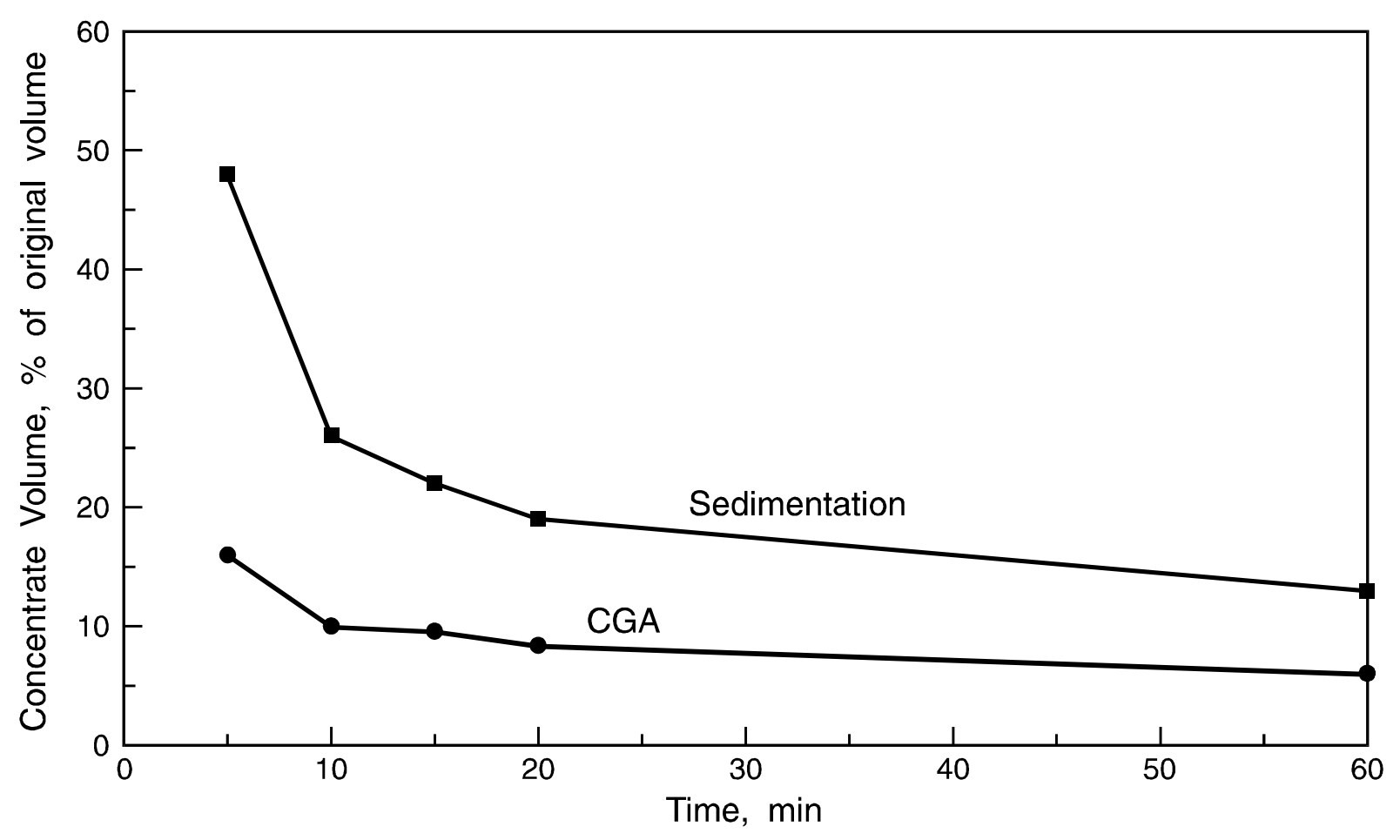

Figure 12. Sludge/Foam Volume Versus Separation Time, Colorado Drainage Sample, pH 6.1, Triton X-100 Surfactant

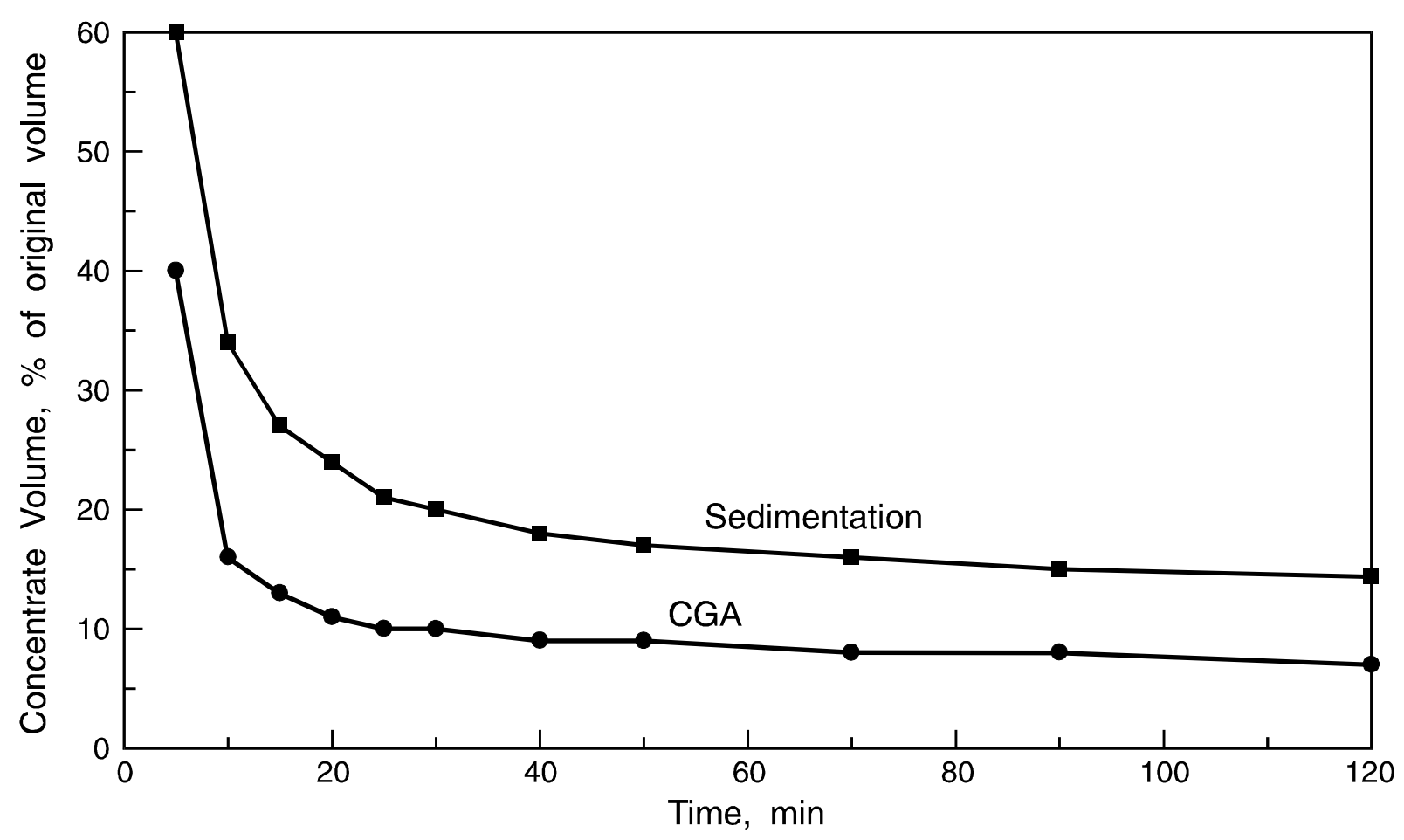

Figure 13. Sludge/Foam Volume Versus Separation Time, Colorado Drainage Sample, pH 6.7, Triton X-100 Surfactant 


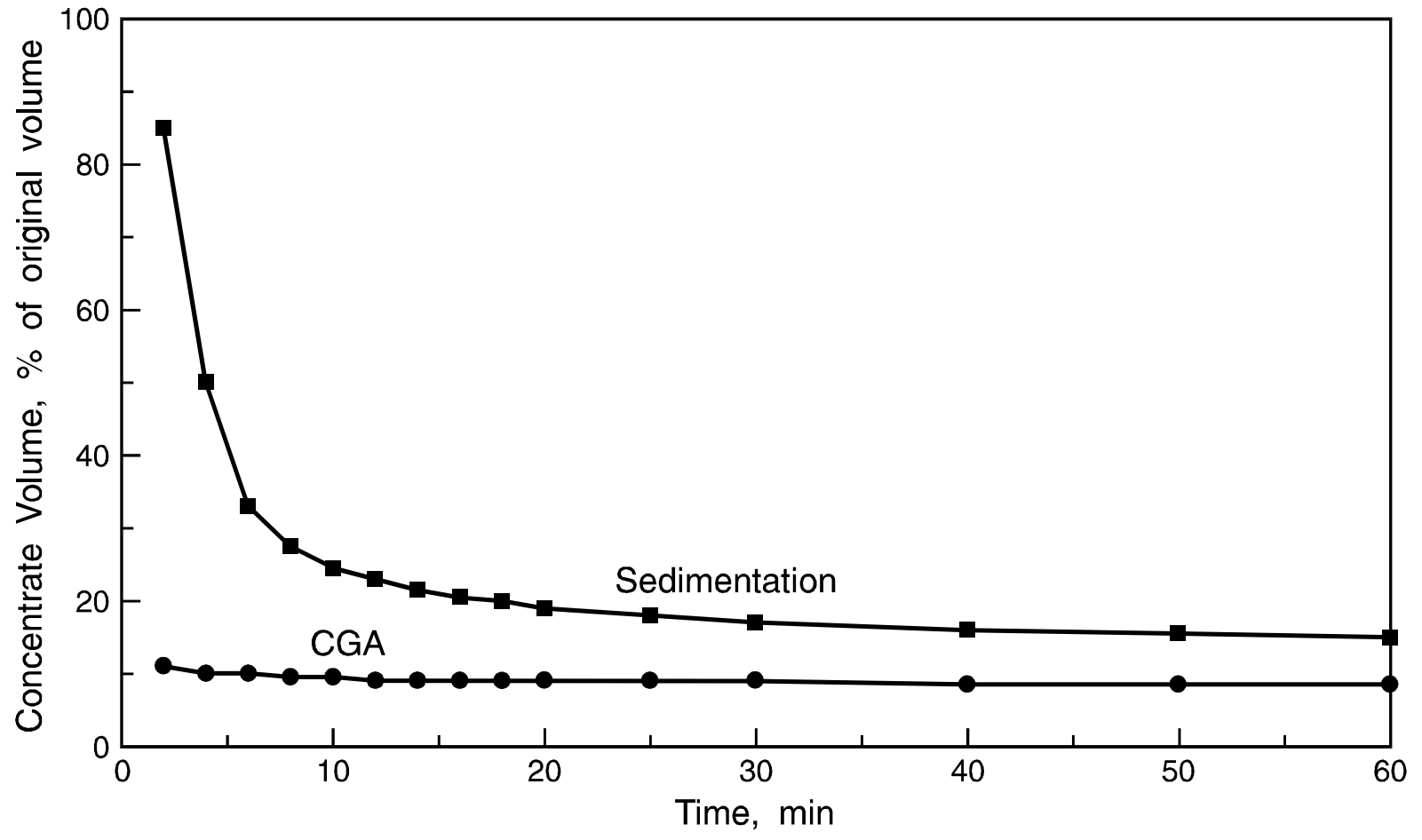

Figure 14. Sludge/Foam Volume Versus Separation Time, Colorado Drainage Sample, pH 6.4, Betz SF 5100 Surfactant 


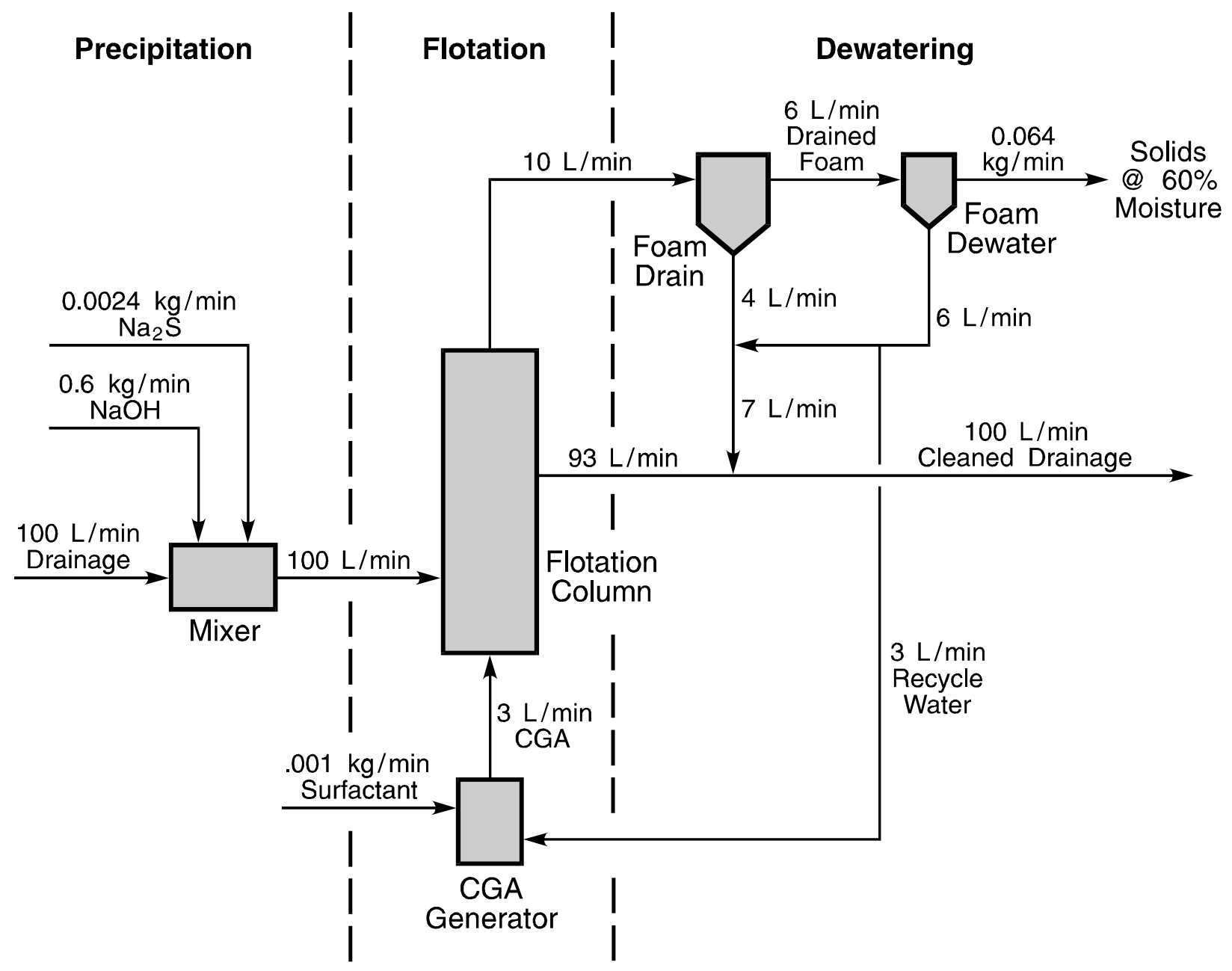

Figure 15. Simplified Process Flow Sheet for $100 \mathrm{~L} / \mathrm{min}$ Process Demonstration Unit 